\title{
NASA's In-Situ Resource Utilization Project: Current Accomplishments and Exciting Future Plans
}

\author{
William E. Larson' \\ NASA-Kennedy Space Center ${ }^{\prime}$, Kennedy Space Center, FL, 32899 \\ Gerald B. Sanders ${ }^{2}$ \\ NASA-Johnson Space Center ${ }^{2}$, Houston, TX, 77058 \\ Kurt R. Sacksteder, $\mathrm{PhD}^{3}$ \\ NASA-Glenn Research Center ${ }^{3}$, Cleveland, Ohio, 44135
}

\section{Introduction}

The utilization of Space resources has been identified in publications for over 40 years for its potential as a "game changing" technology for the human exploration of Space. It is called "game changing" because of the mass leverage possible when local resources at the exploration destination are used to reduce or even eliminate resources that are brought from the Earth. NASA, under the Exploration Technology Development Program has made significant investments in the development of Space resource utilization technologies as a part of the In-Situ Resource Utilization (ISRU) project. Over the last four years, the ISRU project has taken what was essentially an academic topic with lots of experimentation but little engineering and produced near-full-scale systems that have been demonstrated. In 2008 \& again in early 2010 , systems that could produce oxygen from lunar soils (or their terrestrial analogs) were tested at a lunar analog site on a volcano in Hawaii. These demonstrations included collaborations with International Partners that made significant contributions to the tests. The proposed federal budget for Fiscal Year 2011 encourages the continued development and demonstration of ISRU. However it goes beyond what the project is currently doing and directs that the scope of the project be expanded to cover destinations throughout the inner solar system with the potential for flight demonstrations. This paper will briefly cover the past accomplishments of the ISRU project then move to a discussion of the plans for the project's future as NASA moves to explore a new paradigm for Space Exploration that includes orbital fuel depots and even refueling on other planetary bodies in the solar system.

\section{Lunar ISRU Development and Testing}

Over the past few years, the ISRU project has been focused on meeting the needs of the Constellation program. After several iterations of NASA study teams, the emerging consensus was that the primary role of ISRU for a Lunar Outpost would be the production of oxygen. The studies indicated that the Outpost would need approximately one metric ton of oxygen each year to close the life support loop. Therefore the ISRU project significantly narrowed its focus to insure that this capability was well in hand by the scheduled PDR for the Lunar Surface Systems design, scheduled for 2014.

"Mining" the moon for oxygen has similarities to mining here on earth. The first step in any mining process is to locate areas that have the potential for the ore of interest, and then perform local assessment to pinpoint and assess the viability of the ore body. If the ore body is economically viable mining operations begin, the ore is processed for product and the waste disposed of. Eventually, the mine site is remediated to return it to a more natural state.

Utilizing Space resources will require a cycle similar to the terrestrial model. The Space resources cycle is shown in Figure 1. NASA has already taken the first step by using Science Missions to globally assess the lunar resources available. Missions like Lunar Prospector, Lunar Reconnaissance Orbiter and the Lunar Crater Observation and Sensing Satellite have shown that there are two possible sources of oxygen on the lunar surface, the regolith and water ice in the shadowed regions of the poles. Recent data released from the NASA funded Moon Mineralogy Mapper Instrument flown on India's Chandrayann-1 orbiter shows that even in sunlit regions in the

\footnotetext{
${ }^{1}$ ISRU Technology Development Project Manager, Mail Code NE-I2, Member.

${ }^{2}$ In-Situ Resource Utilization Lead for Lunar Surface Systems, Mail Code EP, Member.

${ }^{3}$ Research Scientist, Mail Code REC0, Associate Fellow.
} 
higher latitudes there are hydroxyls present. So with this data in hand, the next step in the process is to locally characterize the resources. To conduct that mission NASA has been developing a resource prospecting payload called RESOLVE (Regolith Environmental Science and Oxygen \& Lunar Volatiles Extraction). RESOLVE is designed to search for and quantify water ice located up to a meter beneath the lunar surface. It is also capable of performing a small scale extraction of oxygen from the regolith. Since Apollo samples has given us ground truth on the mineral composition of regolith, NASA has also been pursuing designs to extract oxygen from regolith at a scale approaching the one metric ton needed by an Outpost.

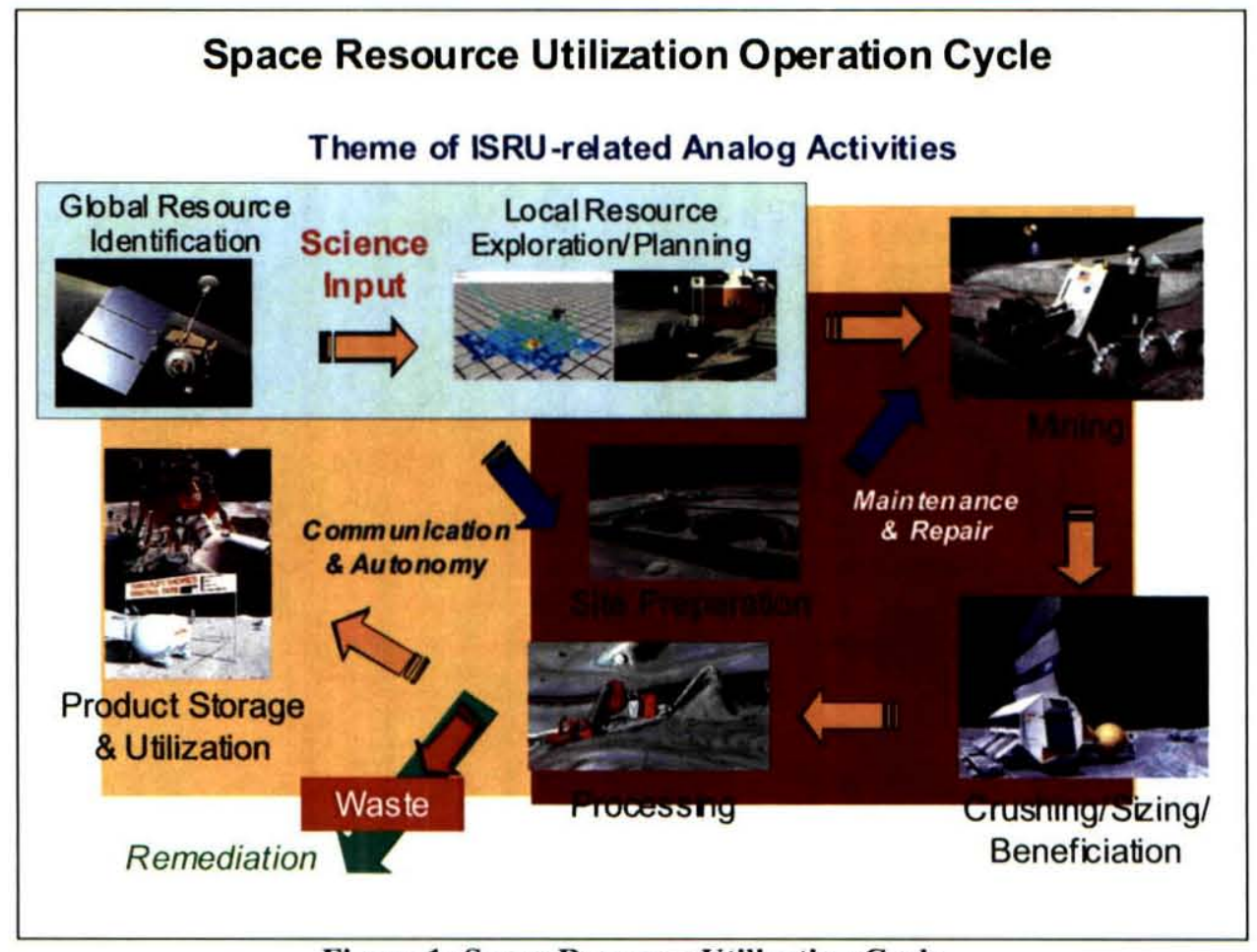

Figure 1: Space Resource Utilization Cycle

Each processing system under development has the same basic architecture. Each needs to be able to take regolith delivered to a hopper by a mobility platform, preprocess it for size and mineral content then deliver it into a processing plant where the oxygen would be extracted. The oxygen would then be passed off to the cryogenic storage system for liquefaction.

There are a multitude of chemistries that have been proposed in literature for the reduction of lunar soil for oxygen, but NASA ended up selecting three for development, Hydrogen Reduction, Carbothermal Reduction and Molten Oxide Electrolysis. Each chemistry has strengths and weaknesses, with Hydrogen Reduction being the simplest and lowest risk, Molten Oxide Electrolysis being high risk, but very high yield and Carbothermal falling somewhere in the middle.

Over the last four years NASA's ISRU project has taken RESOLVE, Hydrogen \& Carbothermal reduction from concept phase through a prototype phase and to fully operational systems. Each of them has been tested at a lunar analog field test where the soil has great similarity to the moon. Each of the systems and their field test will be described in the paragraphs below. Molten Oxide Electrolysis remains under development but it has not yet emerged from the laboratory test phase of development.

\section{A. Resource Prospecting}

Ever since Lunar Prospector detected elevated levels of hydrogen at the lunar poles, there has been considerable debate in the scientific community as to its form and concentration. However, with the impact of LCROSS in the crater Cabeus A in the southern polar region of the moon in October of 2009, it is clear that there is water ice in the 
permanently shadowed regions of the poles. Whether this ice is reasonably accessible as a resource remains an open question. RESOLVE is being designed to answer many of these questions.

RESOLVE will be delivered to the moon on a mobility system so that it can prospect in numerous locations. The first step in the analysis process is to utilize a coring drill to acquire a one meter sample. The core is delivered in segments to a reactor where it is heated slowly to 150 degrees centigrade. As the sample is heated it is monitored by a instruments to detect and quantify the gases being released. In the current version of RESOLVE, a gas chromatograph (GC) was used to analyze the gases. In the flight version of RESOLVE, a mass spectrometer will be added to the exhaust of the GC to provide a more complete analysis of the samples. Any water that is released is captured in some desiccant beds for later electrolysis. After the analysis of volatiles is complete RESOLVE uses the reactor to conduct an oxygen production experiment using the hydrogen reduction process. RESOLVE is designed to evaluate a minimum of ten sample sites, though it is believed that it will be capable of many more.

RESOLVE is being developed in partnership with the Canadian Space Agency, who is providing some of the critical subsystems, like the coring drill and some of the avionics. Ultimately the mission profile for RESOLVE will be determined by the power system available for the mobility system. The payload has a target power requirement of 200 watts peak, and an experiment mass of 60 kilograms.

The RESOLVE project began in 2005. During the first 18 months each of the subsystems was breadboarded and tested. The hardware in this first generation was not integrated as a whole because the initial designs did not lend themselves to easy integration and packaging. However, the data collected gave the design team great confidence that they were ready to proceed with a second generation design that would be flight-like in many ways. The second generation analysis system is shown on the left in Figure 2. This unit was integrated and tested in 2008 with a mobility system designed under a NASA grant by the Carnegie Mellon University. The rover which is called Scarab, due to its bug-like appearance, was designed specifically to carry the Canadian-supplied drill system and the volatiles analysis system. The integrated hardware is shown at the 2008 ISRU field test at a lunar analog test site in Hawaii provided by the Pacific International Space Center for Exploration Systems (PISCES).
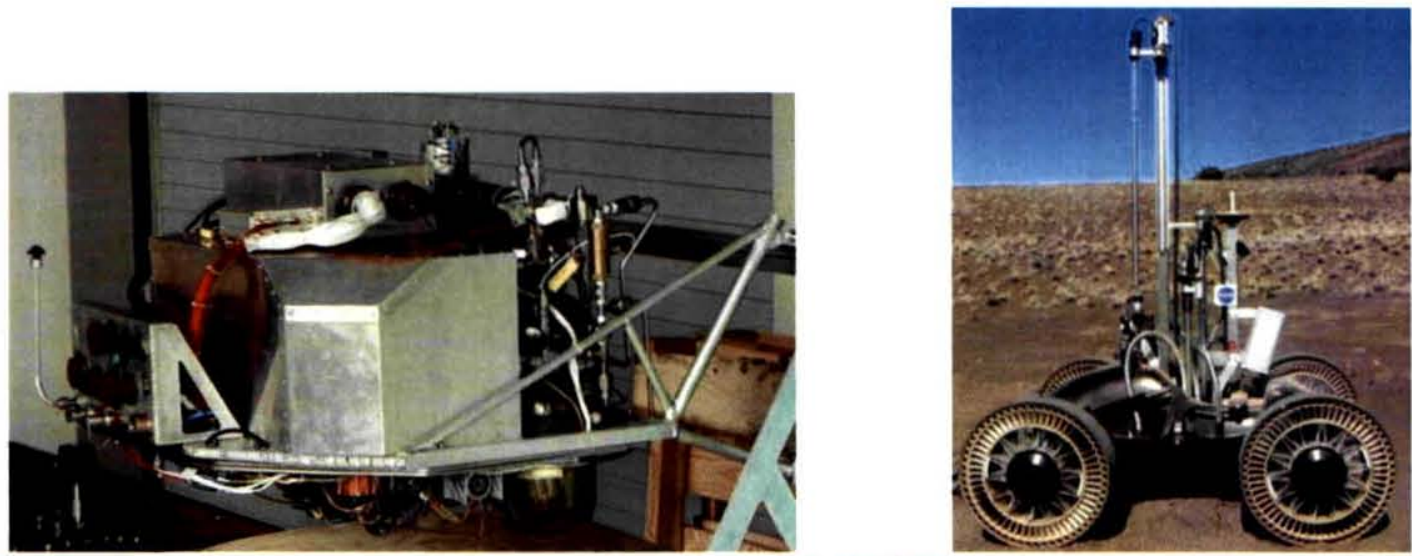

Figure 2: RESOLVE Analysis System (Left); Scarab \& RESOLVE under test in Hawaii (right)

In 2010, RESOLVE was taken back to the field again for further testing. This time the Canadian Space Agency supplied the mobility platform for RESOLVE. Due to the miniaturization of the power and control systems, RESOLVE was able to rove into the bottom of a volcanic cinder cone where it collected samples and analyzed the soil, simulating one of the possible scenarios for a lunar mission. As a result of these two tests the team is ready to move forward with a flight design.

\section{B. Hydrogen Reduction}

Hydrogen Reduction is the simplest lunar oxygen production process. It requires the mixing of hydrogen gas with the regolith at around 950 degrees Centigrade. The hydrogen reacts with some of the iron oxides in the lunar soil to produce water vapor. The water vapor is condensed, cleaned and then electrolyzed to produce oxygen. The hydrogen produced by the electrolysis step is recycled back into the reactor to produce more water. This process has a lot of practical advantages. Not only is the chemistry simple, but the temperatures are low enough that the regolith stays in a granular form and avoids the complexities of dealing with consolidated materials. Unfortunately, the portion of the lunar regolith that will react with the hydrogen at these temperatures is generally below $10 \%$ and 
perhaps much lower at the poles where a Outpost is likely to be located, so the amount of regolith that must be processed to make a metric ton of oxygen is quite high.

While the chemical process for hydrogen reduction is straightforward, there were many ideas on how such a reactor should be designed. The challenges of operating a system like this in the lunar environment are significant. Not only are there significant temperature extremes, but the reactor must interact with the abrasive lunar soil repeatedly and still be able to seal against the high vacuum found on the moon. So beginning in 2005 NASA began funding two separate design approaches to a hydrogen reduction reactor. One design team was led by engineers at the Johnson Space Center (JSC) with support from the Kennedy Space Center (KSC). The other system was awarded through a competitive process to Lockheed Martin Space Systems in Colorado. The JSC system utilized vertical reactor that was fed from the top by an inclined auger that brought soil up from a ground level hopper. The soil was stirred using a vertical auger inside the reactor as the hydrogen gas was injected. A condenser stage followed to collect the water produced by the reaction. The water then passed through a cleanup system before moving to the electrolysis subsystem. Lockheed Martin took a different approach to feed and mixing system. They used a horizontal sleeved auger which was inserted between redundant gate valves. The sleeve kept the soil from ever coming into contact with the valve seats. The reactor itself was conceptually like a cement mixing truck with a horizontal reactor that had internal spiral flutes. Depending on the direction of the rotation, the flutes either helped pull the soil into the reactor or move it up and out to the horizontal auger system. Once loaded the reactor was rotated to create the mixing of the soil and the hydrogen. After that, the process was the same, with a condenser, cleanup and electrolysis system. Both units used resistive heating elements to generate the heat for the reaction.
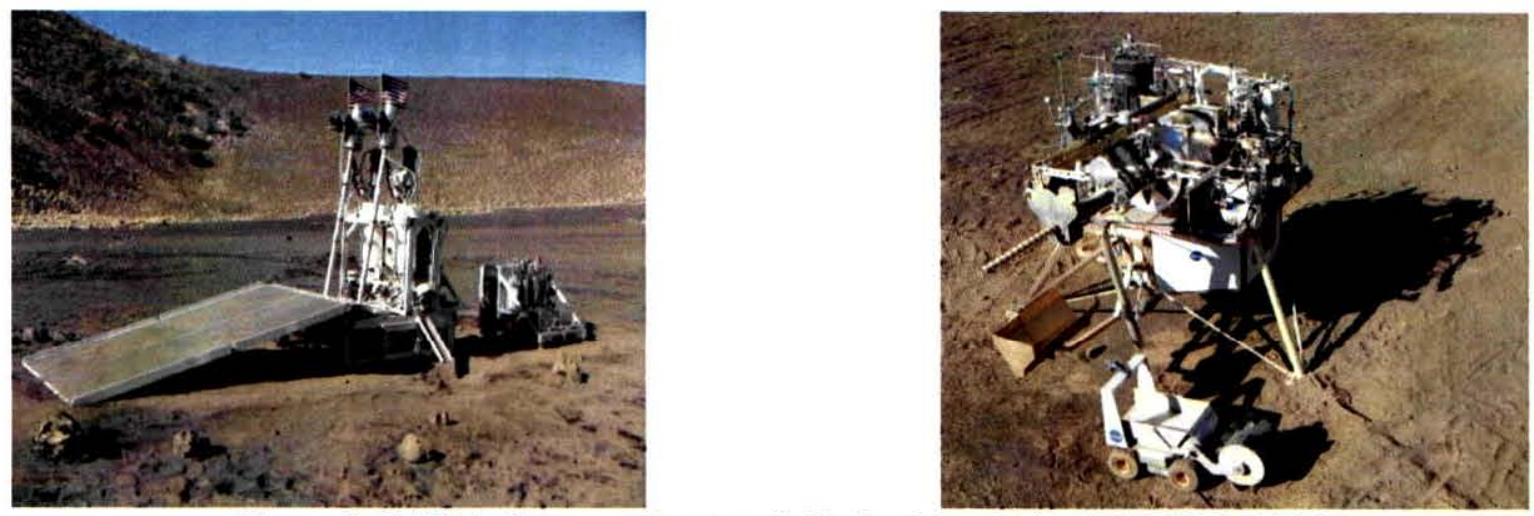

Figure 3: NASA's Roxygen Reactor (left); Lockheed Martin's PILOT (right)

In 2008 both of these systems were taken to the PISCES test site in Hawaii. Over a two week period, the systems were assembled in the field and tested repeatedly. Although there were some hardware failures all of them created only minor delays and the test was deemed a success. As with any field test the team learned a lot and improvements were incorporated into the next generation of hardware. In general, the auger feed systems worked well, but had some wear and tear issues. For the JSC reactors the vertical auger system, while it worked was deemed a weak point in the design and it was decided that the next generation of hardware would utilize a gas fluidization approach. Lockheed Martin's system concept performed well, but unfortunately budget reductions in NASA's technology program caused the project to be halted.

\section{Carbothermal Reduction}

The Carbothermal Reduction System was the second of the three oxygen production processes to emerge from the laboratory into the field. This system required the maturation of two technologies, the carbothermal reactor, designed by Orbital Technologies Incorporated (Orbitec) and the system to capture and utilize solar thermal energy to heat the soil designed by Physical Science Incorporated (PSI). Both of these technologies had their beginnings in the Small Business Innovative Research (SBIR) program and have made significant strides over the last five years.

The carbothermal reaction is a much higher temperature reaction than the previously described hydrogen reduction. The temperatures are so high that the soil actually becomes liquid. Once the melt is established, methane gas is introduced to the reaction chamber. When the methane comes into contact with the high temperature melt, it decomposes into Carbon and Hydrogen. The Carbon is absorbed into the melt where it reacts with some of the minerals and releases carbon monoxide. The carbon monoxide and hydrogen gas are then sent to into a methanation reactor where in the presence of a catalyst methane and water are generated. The water is electrolyzed to obtain the 
oxygen product desired and the hydrogen is sent back into the methanation reactor. This process extracts a much larger percentage of the oxygen available in the regolith, but as was mentioned in the introduction, that extraction efficiency does come with some challenges.

The first challenge that Orbitec had to address was how to deal with this molten mass inside a reactor. Their solution was to use the regolith itself as the crucible for the reaction. Lunar materials are known to be poor conductors of heat. So using a point source of heat it was possible to melt a hemispherical pool of regolith in the center of a bed of regolith. The regolith insulates the reactor from the molten material and then when the reaction is complete and the material has solidified it can be simply plucked out of the bed of regolith, smoothed over and is immediately ready for another batch.

While the Orbitec carbothermal system utilized the same horizontal auger and gate valve design developed by Lockheed Martin to fill their reactor chamber, NASA decided to take a different approach to the feed system that delivered soil to the carbothermal system's upper hopper. Instead of an auger based system used in previous years, another emerging SBIR technology developed by Honeybee Robotics was employed. The system utilizes gas to move the regolith from ground level to the upper hopper. Cyclone separators remove the granular material from the gas stream and the gas is recirculated to close the transport loop. This system is attractive for the moon because it has very few moving parts that come in contact with the regolith. Plus, in the moon's low gravity field, it takes very little gas flow to move a large amount of regolith. For the field demo a small compressor was used to provide the gas flow, but in lunar applications a small amount of the produced oxygen could be used to transport the regolith. The system performed well in the field tests and offers NASA another good option for transporting granular material in many of our designs.

Another significant challenge for the carbothermal process is the amount of thermal energy required to melt the regolith. Resistive heaters were not an attractive option as they would have to come in contact with the molten regolith and the highly reactive environment in the melt would damage the heaters. However, there is another abundant thermal energy source available on the moon. The sun delivers tremendous amounts of thermal energy to the surface of the moon. But collecting it, focusing it and delivering it into the reactor was the challenge that PSI undertook. The approach taken utilized parabolic collectors coupled with secondary mirrors to focus the infrared energy into a fiber optic bundle. The fiber optical cable allowed the energy to be routed wherever it was needed. In this case, it was routed to the top of the carbothermal reactor where the infrared energy was transferred through a quartz rod and into the reactor. Though there are losses in the system at each transfer point, more than half of the energy collected is delivered into the chamber, melting the regolith in the reactor in 10 or 15 seconds. The system was even more effective when tested in Hawaii where the test site was 9000 feet above sea level reducing the attenuating effects of the atmosphere.
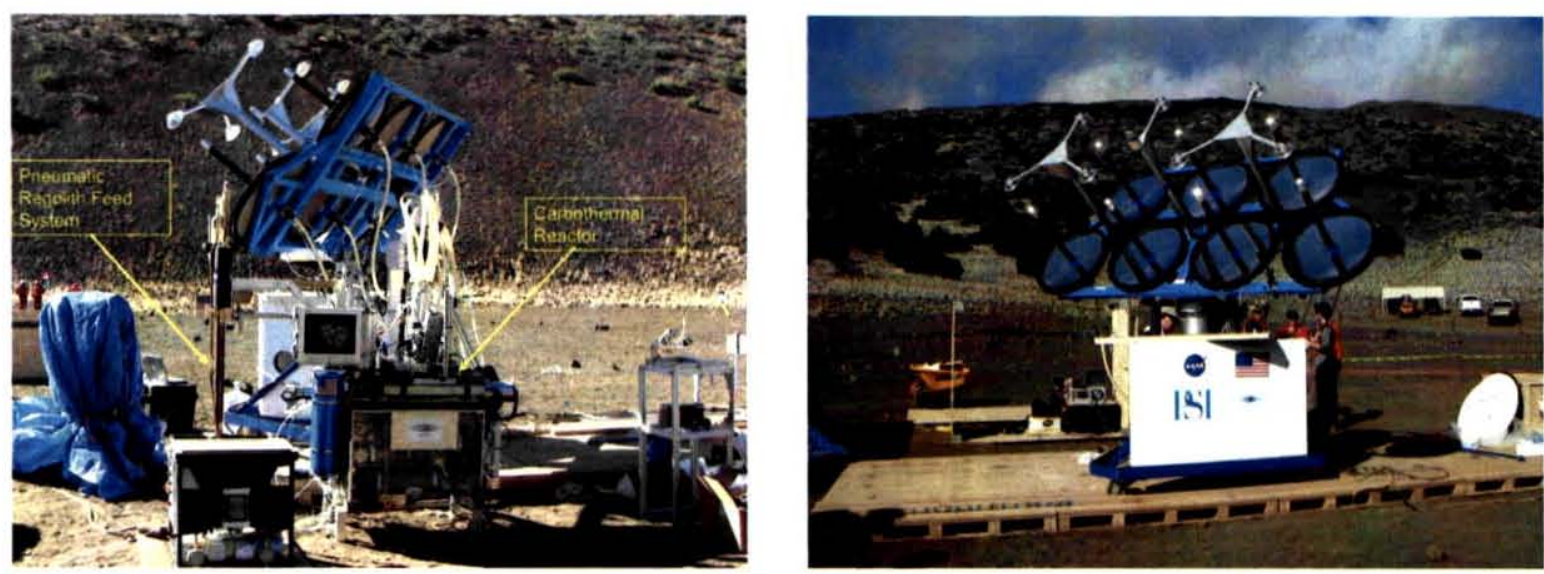

Figure 4: Carbothermal Reactor and Solar Concentrator Array

Both systems performed well during their field trial. The weather did not cooperate with us completely as we had several days where either high clouds reduced the energy delivered to the reactor or heavy clouds moved in for a portion of the day. But in spite of these setbacks the team completed 16 cycles of the reactor with an oxygen yield close to $10 \%$. 


\section{Closing the ISRU Cycle}

The 2010 field test also was used to advance our ability to close the ISRU cycle. Completing this cycle from acquisition of regolith through the utilization of the products had never been attempted before. We also wanted to start taking steps towards closing the fluids and power cycles for ISRU as well. To accomplish this we needed to bring together several disciplines that were not members of the ISRU community. So with the cooperation of our international partners and the Energy Systems Division at JSC we came very close to closing the entire cycle.

On the front end of the production cycle, the CSA, through a contract with the Northern Centre for Advanced Technology (NORCAT), provided a lunar "front end loader" to fill our supply hopper with soil. Their "front end loader" utilized the same mobility platform base that carried the RESOLVE payload, but though a well thought out design that allowed quick change out of accessories, it became a lift, haul, dump (LHD) rover. The rover with the LHD implement attached as well as its autonomous navigation triangulating lidar system is shown in Figure 5 below.

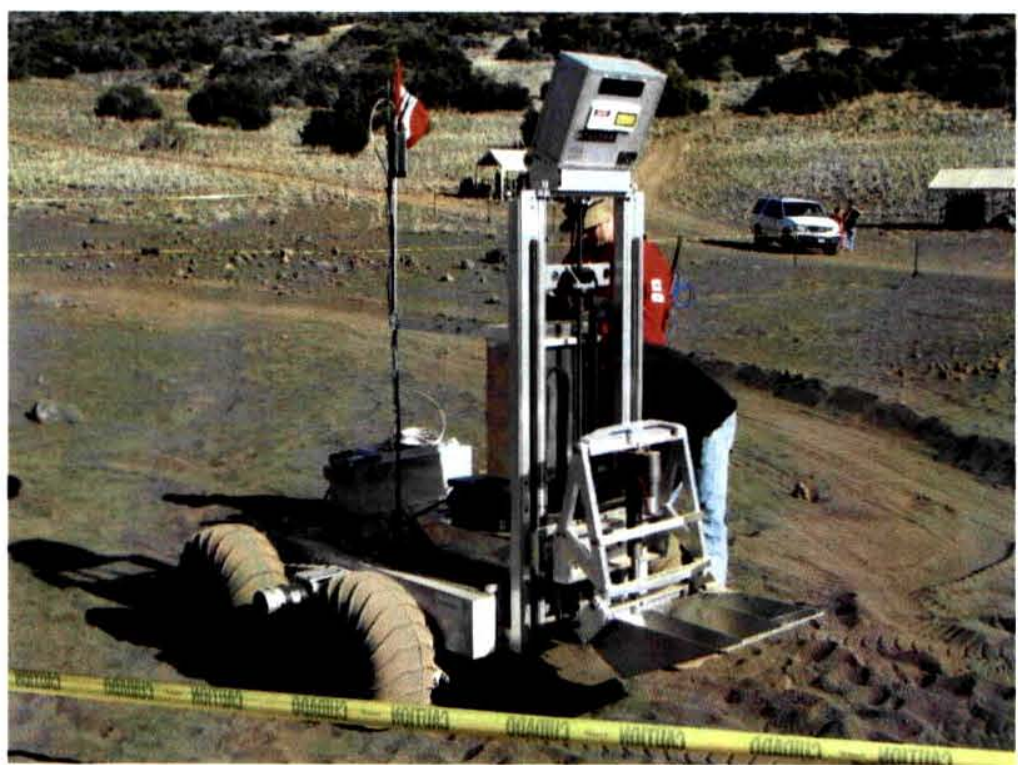

Figure 5: CSA Rover and Regolith Delivery Implement

The oxygen produced from the water created by the carbothermal reactor was sent to a cryogenic liquefaction and storage system. Over the course of the field test we stored all of the oxygen produced. The utilization of the oxygen was then demonstrated through a series of thruster firings. The thruster and cryogenic system, developed by JSC's Energy Systems division was a methane/ oxygen system. This is fuel combination is significant because it is the likely fuel/oxidizer combination for an ascent vehicle when we send humans to Mars.

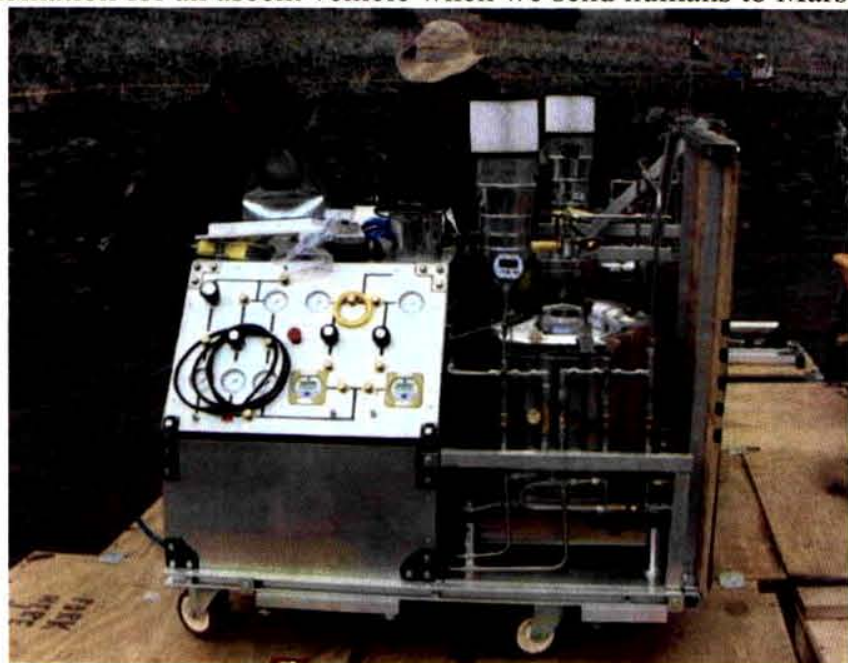

Figure 6: Cryogenic Liquefaction \& Storage System

American Institute of Aeronautics and Astronautics 
On the power/fluids side of the cycle we again turned to our international partners who provided a fuel cell system that was used to provide the electrical energy needed to operate the control systems for the carbothermal and solar concentrator sun tracker. The addition of the fuel cell to the field test allowed us to almost completely close the simulated outpost energy cycle for ISRU. As stated above the fuel cell supplied all of the electricity needs to run the systems and the electrolysis system was able to take the water from the fuel cell and regenerate the reactants needed to run the cell each day. All we were lacking to completely close the loop was a photovoltaic system which was needed to provide the power for the electrolysis of the water.

\section{An Exciting Future for ISRU}

The newly proposed United States Space Policy calls for increased investment in technologies that will enable human exploration of the solar system. The In-Situ Resource Utilization (ISRU), led by KSC, stands to benefit from this increased investment. It is one of the technologies that NASA was specifically directed to pursue by the Office of Management and Budget when the budget was released on February 1st.

As described in the preceding section, ISRU has made significant strides in the area of oxygen production from lunar regolith. ISRU is no longer a laboratory experiment. It has been taken in the field to be tested at lunar analogs and integrated with many other technologies. Unfortunately progress was always constrained by funding limitations as budget problems within the Agency and within Constellation limited the amount of money available to invest in technology projects. This also caused the ISRU project to become more and more of an in-house activity as we tried to maintain our core competencies.

The new technology program proposed by the President will be quite different from the current program. There will be increase focus on external participation and multiple sources of funding. It will also allow for the scope of the ISRU project to be broadened beyond oxygen production to the use of space resources to provide fuel, water, metals, plastics and even the manufacture of spare parts. While there is much angst being expressed over the lack of a launch vehicle program within NASA, the lack of a launch vehicle program actually offers some hope that technology budgets will remain stable for a few years and perhaps even grow.

The new technology development structure within NASA will have several programs that could potentially fund ISRU activities. One of the Programs, Enabling Technology Development and Demonstration (ETDD), will be the home of the ISRU Domain. There is an additional program called the Space Technology Program that is managed by the Office of the Chief Technologist that is also likely to fund low TRL ISRU development. This program is intended to fund technologies that cross cut NASA's missions and can be "game changing." The majority of the development under the Space Technology Program will be awarded competitively allowing greater opportunity for industry and academia to contribute to NASA's development efforts. In addition to these two technology development programs, two flight programs have been proposed. The Exploration Robotics Precursors and Flagship Technology Demonstrations programs will provide opportunities for ISRU to finally be tested in Space.

The ETDD program will provide Domain funding to allow NASA to maintain its core technical expertise. The Domain will provide the technical leadership; establishing the technology development strategy and perform the system integration and development activities for ISRU. The ETDD program will also have two additional elements, Demonstrations and a Competitive Technology Development element. Each Demonstration Project is framed around answering a key question derived from architectural studies. Demonstration Project Managers, who are separate from the Domain Managers, competitively select technologies to demonstrate solutions to those key questions. It is expected that technologies from several Foundational Technology Domains will be chosen for inclusion in the Demonstrations. One of the first demonstration projects that will begin in FY11 is a lunar volatiles ground truth mission in partnership with the Exploration Robotics Precursor Program, notionally targeted for the middle of this decade. The starting point for this development activity will be the RESOLVE project, described in the previous section.

A significant portion of the technology development under the ETDD program will be conducted through competitive Broad Area Announcements that will cover all of the ETDD technology domains. The competitions between NASA technologists and external providers will be conducted separately. However, for the external competitions, partnerships will be encouraged between the external researchers and a NASA Center. The budget for the ETDD program is somewhat constrained initially, but is slated to grow over the next five years. As the budget grows the competitively awarded portion of the funding will grow to at least $50 \%$ or greater. The projected budget for ETDD is shown in Figure 7. 


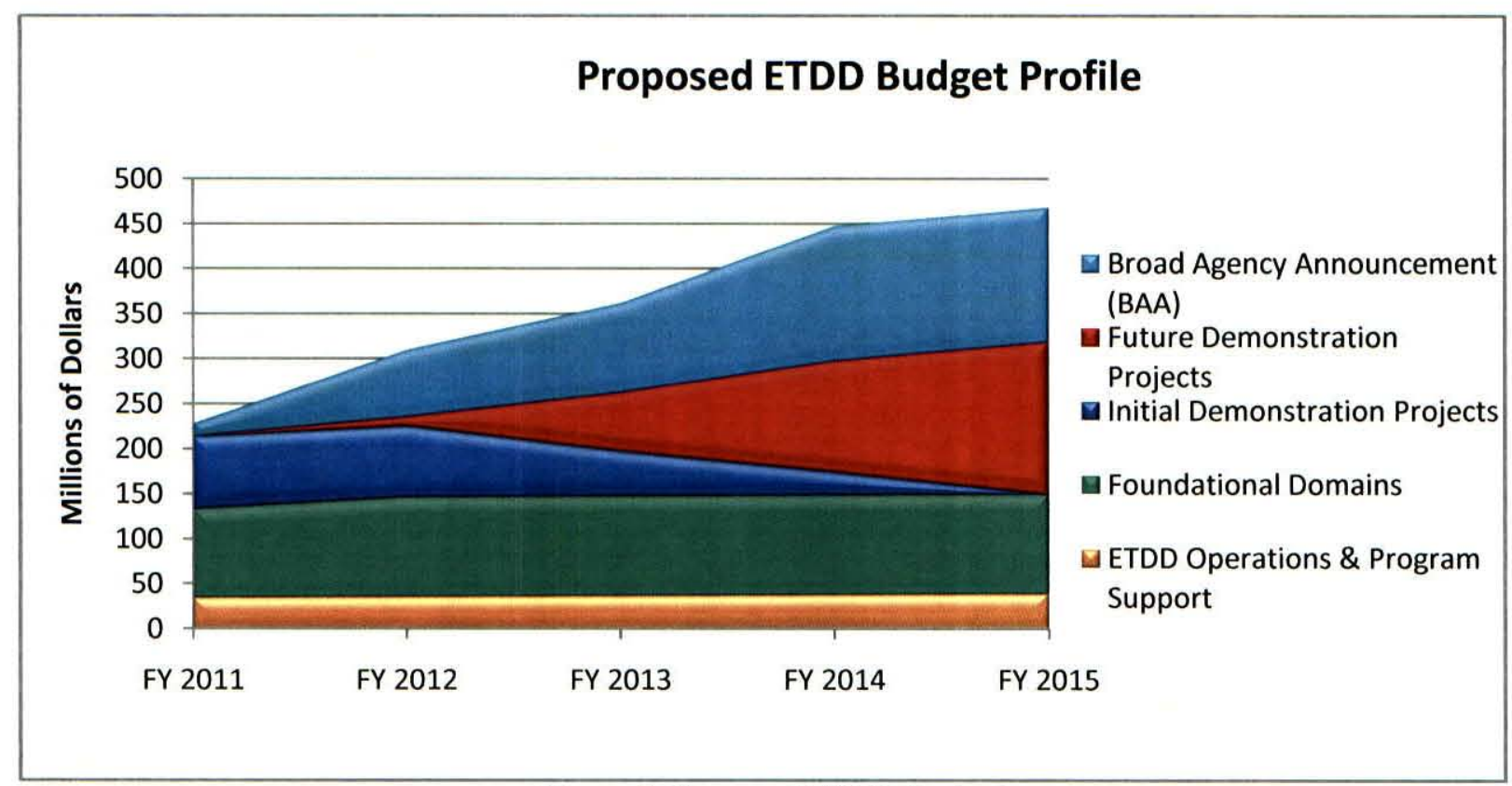

Figure 7: Proposed ETDD Budget

Over the next five to ten years the ISRU Domain will focus its energies on the flight opportunities that are emerging from the Flagship, Robotic Precursor and International programs. There are several missions to the moon that are in the planning stages, some of which are internationally led. So the project will try to follow up on the lunar volatiles mission with an oxygen production mission to demonstrate that we can reliably produce large quantities of oxygen from the lunar regolith. Mars is also in the crosshairs for the ISRU project. The Earth to Mars launch window in 2018 finds the planets in a very favorable position that will allow NASA to deliver a much larger payload to the surface than during typical launch windows. Therefore this will be an ideal time to send a very robust ISRU payload to Mars. We will target our efforts to place a fuel and oxygen production system on this Lander to demonstrate a key capability called for by the Mars Design Reference Mission. It will also be highly desirable to prospect for subsurface water on Mars to see if it can be extracted to eliminate the need to bring hydrogen and water from earth. There is also planning underway to send a robotic probe to a Near Earth Asteroid to evaluate the environment for eventual human exploration. ISRU prospecting missions are certainly in order to determine if these NEO's contain resource that could impact NASA's exploration architecture.

\section{Conclusion}

In conclusion, the ISRU Project has made significant strides over the last five years to move ISRU out of the laboratory and into realistic field tests. These field tests significantly increased our readiness to deliver the ability to utilize Space resources to the Exploration Program as we used these field tests to begin the process of integrating the with the many other technical domains required such as power, cryogenic liquefaction \& storage and even propulsion systems. It is hoped that flight opportunities will emerge nationally and internationally to allow us to demonstrate this ISRU technology on the surface of the moon sometime in this decade.

The future also looks bright for continued ISRU development for the moon and beyond. The President's budget proposal provides a renewed focus on technology development. A significant part of the technology development portfolio will focus upon technologies that impact human exploration beyond Low Earth Orbit. ISRU is clearly defined in the budget as one of the key technologies needed for deep space exploration and will receive greater focus and funding than ISRU ever had under the Constellation Program. While the final budget for ISRU will still be subject to Congressional appropriation, it is believed that even if the President's budget proposal is modified, ISRU will still continue to be developed to improve our ability to explore deep into the solar system by using its abundant resources. 


\section{Acknowledgments}

The authors would like to acknowledge the many fine men and women that work on the ISRU project within NASA and our support Contractors. Without their "dedication to the cause" the ISRU project would not have been able to make the significant progress described in this paper. 


\section{NASA's In-Situ Resource Utilization Project} Current Accomplishments and Exciting Future Plans

William E. Larson

ISRU Technology Development Project Manager

Gerald B. Sanders

ISRU Lead for Lunar Surface Systems

Kurt R. Sacksteder, PhD

ISRU Research Scientist

August 30, 2010 


\section{Topics}

- ETDD Study Team Background

- Program Objectives

- Program Overview

- Relationships to Other Programs

- Program Structure

- Demonstration Projects

- Foundational Technology Domains

- Budget

- Preliminary FY11 Plan 


\section{RESOLVE}

- Resolve work began in FY06The objectives were defined as follows:

- Characterize the Hydrogen/water resource in permanently shadowed crater. Determine type, quantity, and spatial distribution of volatile resources.

- Utilize indirect measurement technique (i.e. neutron spectrometer) to locate and pinpoint site for direct resource characterization

- Extract core sample a minimum of 1 meter length

- Process core in a minimum of 4 segments

- Crush core segments in $1 \mathrm{~mm}$ size particles to evaluate volatile release due to physical processing alone

- Heat crushed core segments in controlled steps to measure volatile constituent and quantity release as a function of temperature

- Measure type and amount of volatiles released (H2, He, N2, water, ammonia, methane)

- Demonstrate capture and separation of hydrogen and water (if present)

- Measure mineral/chemical and geo-technical properties of permanently shadowed crater regolith to support subsequent excavation hardware design

- Measure regolith and environment temperature in permanently shadowed crater

- Repeat process for a minimum of 3 sites and nominal mission of 10 and highly desired 20+ sites for $90 \%$ confidence in null water detection.

- Continuous operation in permanent shadow for at least 7 Earth days for rover missions.

- The mission drivers were to

- Determine hydrogen concentration outside of the permanently shadowed crater (early 2011 to 14)

- Determine hydrogen source form, concentration, and spatial distribution inside of the permanently shadowed crater (early 2011 to 14)

- Demonstrate subscale polar volatile extraction and separation fur extended period of time; demonstrate crater entry/exit (mid 2015 to 18)

- Deploy certified operational resource extraction and processing system at start of Outpost 


\section{Summary of Accomplishments}

- Developed bench-scale non-integrated components for lower TRL testing in CY 06/07 (referred to as RESOLVE Engineering Breadboard Unit 1) 


\section{Summary of Accomplishments}

- Developed field-scale, integrated RESOLVE unit in CY07/08 for TRL 6 testing (referred to as RESOLVE EBU2)

- November 2008 conducted the first field deployment of RESOLVE on Mauna Kea Volcano in $\mathrm{HI}$ as part of an international, lunaranalog field campaign.

- RESOLVE mounted in GRC/HRS-funded rover develped by Carneige Mellon University

- Submitted and awarded NSPIRES grant under Moon Mars Analog Mission Announcement to retest RESOLVE in concert with CSA-led analog mission again in $\mathrm{HI}$.

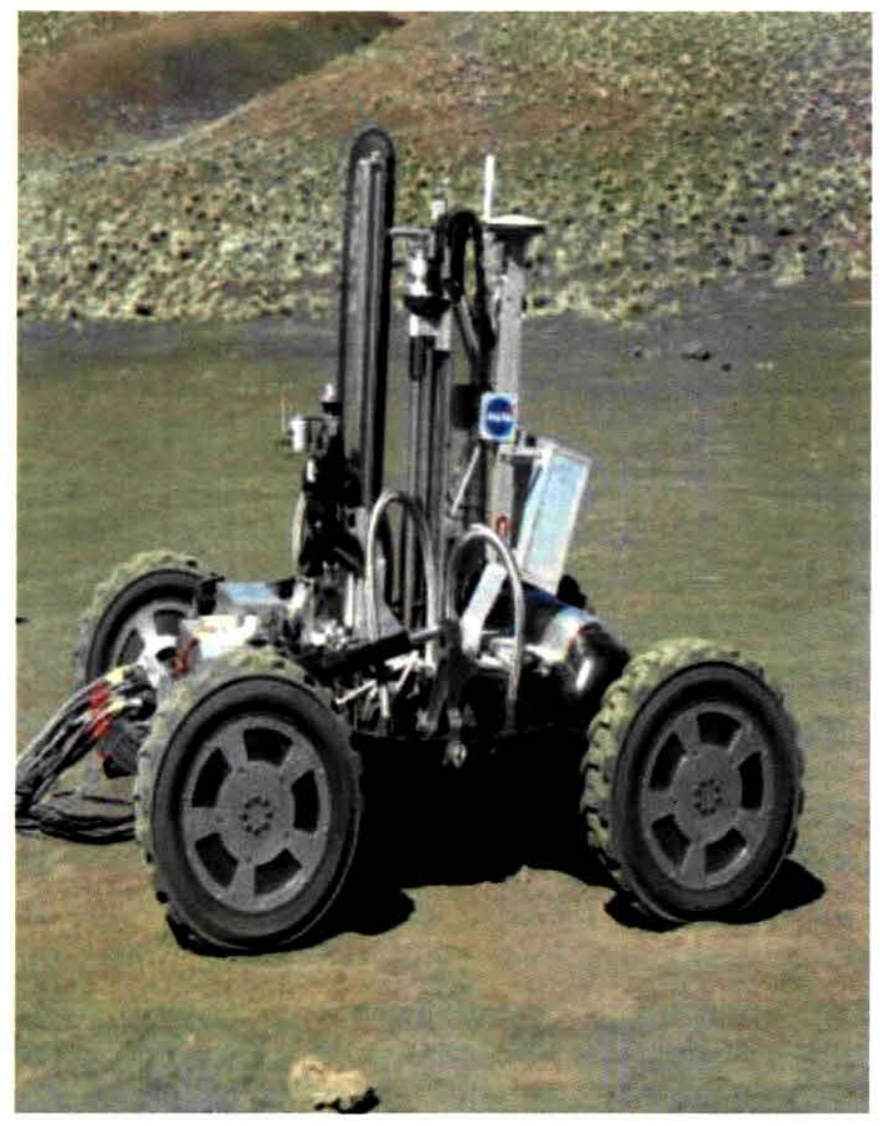




\section{Summary of Accomplishments FY10}

- Minor modifications to RESOLVE made to support loading unit into a CSA-supplied mobility chassis.

- Participated in Jan/Feb 2010 CSA-led lunar analog mission on Mauna Kea using SMD funding to support retest.

- Supported ETDD planning for Lunar Volatiles Demonstration Mission (submitted project plan, budget, and pulled together four center team for project startup).

- Supported "NASA Day on the Hill" at Rayburn Building with RESOLVE in Scarab 


\section{Summary of Accomplishments}

- ROxygen, FY07 - early FY09

- Designed new hydrogen reduction based in-situ oxygen production plant.

- Auger-based feed system and reactor allowed for reliable mixing of reactor feedstock with hydrogen gas to enhance uniformity of the reduction reaction.

- Moderate pressure PEM electrolysis hardware chosen to leverage existing hardware.

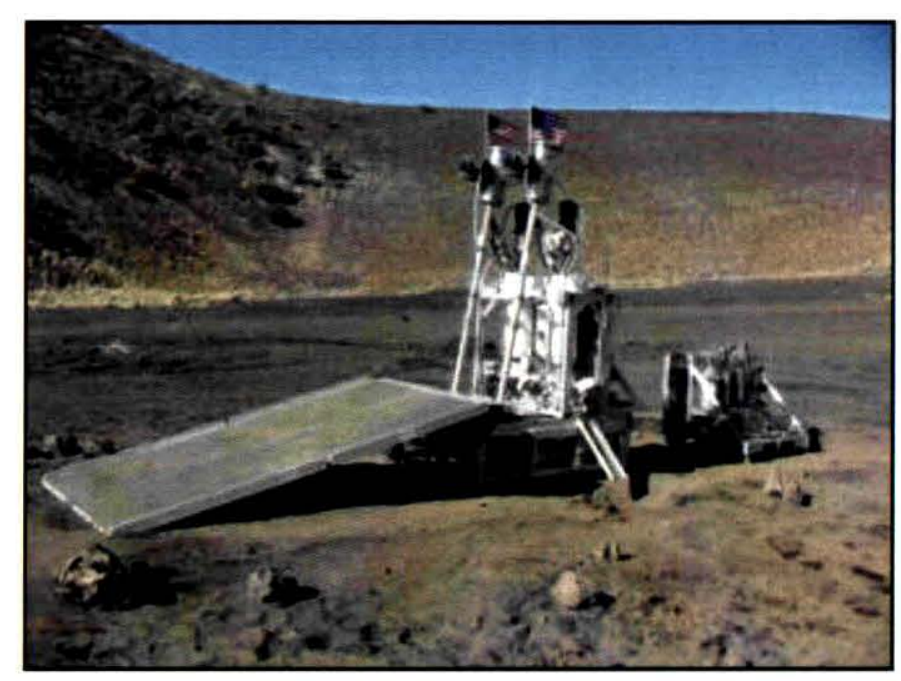

- Non-regenerable water contaminant cleanup system successfully implemented

- Gas phase oxygen storage provided simple, low-power interface for potential oxygen-consumers.

- Field testing of oxygen production plant in Hawaii

- Demonstrated hydrogen reduction and electrolysis operations using in-situ material for reaction feedstock 


\section{PILOT (Lockeed Martin)}
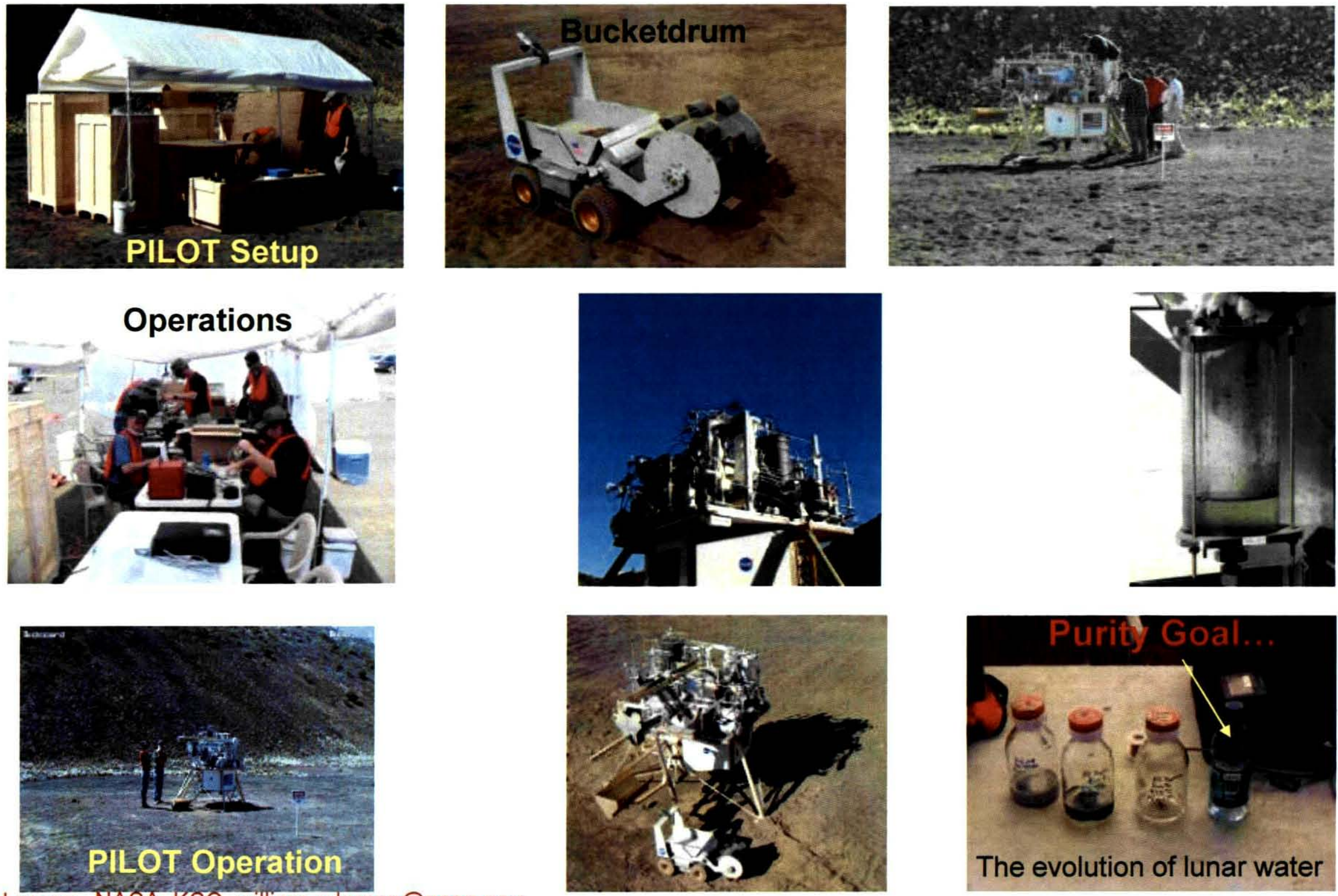


\section{PILOT Field Test Accomplishments}

- 5 Days of field testing

- Demonstrate 6 complete PILOT operations

- Full regolith feed/discharge handling cycles

- 6 hydrogen reduction runs with $12 \mathrm{~kg}$ of tephra

- 4 tests using gas cleanup module

- Significant water generated from regolith on every process run

- First two runs conducted without water clean up, so a significantly acidic water was generated

- Run three used water vapor scrubber and water was visibly cleaner

- Collected a total of $1000 \mathrm{ml}$ of water made from hydrogen reduction of tephra

- Demonstrated back to back test cycles which allowed greatly reduced heat up times on the subsequent run thru successfully demonstrating regolith heat recovery

- All hydrogen gas used during 6 successful hydrogen reduction runs was produced on board with a cathode feed electrolyzer 


\section{A New Exploration Strategy}

- OMB released new program structure, budget and objectives for NASA on February $1^{\text {st. }}$.

- New focus on technology development first, then human exploration second.

- This strategy was the key reason for the recommended cancellation of the Constellation Program

- Congress will have the final say on this and we probably won't get a definitive answer until March 2011.

- As an Executive Branch Agency, NASA is still responsible for developing a plan to execute the President's proposed budget

- NASA established Study Teams to flesh out the new programs and plan content for FY11 and beyond

- Robotic Precursors, Flagship Demonstrations, Enabling Technology Dev \& Demonstration, Space Technology Program, Heavy Lift Propulsion, Participatory Exploration, Human Research Program 


\section{ETDD Study Team Members}

\begin{tabular}{l|l}
\hline NAME & EXPERTISE \\
\hline Chris Moore (Lead/HQ) & Program Management \\
\hline Doug Craig (HQ) & Architecture Studies; Analogs \\
\hline Frank Peri (LaRC) & ETDP Program Manager \\
\hline Chris Culbert (JSC) & Lunar Surface Systems; Robotics \\
\hline Eugene Tu (ARC) & Program Management; Avionics \& Software; EDL \\
\hline Les Johnson (MSFC) & In-Space Propulsion; Program Management \\
\hline Bill Larson (KSC) & In-Situ Resource Utilization; Project Management \\
\hline Peter Hughes (GSFC) & Chief Technologist \\
\hline Carolyn Mercer (GRC) & Energy Storage; Project Management \\
\hline Dan Barta (JSC) & Life Support; Project Management \\
\hline John Warren (HQ) & Nuclear Power \& Propulsion Systems \\
\hline Jason Crusan (HQ) & SOMD Liaison; ISS Utilization \\
\hline Dan Baize (LaRC) & Program Management \\
\hline Christine Solga (HQ) & Resource Analyst \\
\hline
\end{tabular}


Develop, mature, and test enabling technology for human exploration

- Develop and demonstrate prototype systems to feed the Flagship, robotic precursor, and other exploration goals

- Develop long-range, critical technologies to provide the foundation for a broad set of future exploration capabilities

- Provide infusion path for promising, game-changing technologies developed by Space Technology Program

- Assess the feasibility of system and operational concepts resulting from architectural studies by building and testing proof-of-concept systems.

- Develop exploration technologies that may also have terrestrial applications for clean energy and protecting the environment.

In the process of meeting these objectives, ETDD will:

- Seek opportunities to demonstrate technologies using multiple venues and platforms

- Leverage and collaborate with commercial and international partners and other government agencies.

- Promote and foster a national workforce for technical innovation

- Support participatory exploration and education through public engagement in technology demonstrations. 


\section{Program Description:}

- Shorter duration demonstration projects funded at $\$ 100$ million or less, ranging from laboratory experiments to Earth-based field tests and in-space technology demonstrations.

- Near-term development and demonstration of prototype systems to feed Flagship, robotic precursor, and other missions of opportunity.

- Long-range development and maturation of technologies critical to future human exploration missions.

- Infusion path for promising, game-changing technologies developed by Space Technology Program

\section{Approach:}

- Build on technology investments within current ESMD portfolio.

- In FY11, initiate demonstration projects leading to flight experiments on Flagship, robotic precursor, or international missions around 2015.

- NASA was specifically directed to initiate an ISRU Demonstration Project in FY11

- Provide a foundational technology base to mature technology products for future demonstration projects.

- Goal to have over 50 percent of program funding awarded through competition.

- Separate intramural and extramural competitions will be conducted so that NASA centers are not competing against their external partners.

- Projects will be designed to take full advantage of available assets, such as wind tunnels, ground-based analogues, flight test aircraft, suborbital sounding rockets, commercial reusable suborbital vehicles, robotic spacecraft, ISS, and other test platforms. 


\section{ETDD Structure}

\section{Foundational Technology Domains}

- Domains are led by NASA management team

- Aligned with long-range architectural technology needs

- Advance state-of-the-art and knowledge base in key technical disciplines

- Supply mature technologies to ETDD Demo Projects, Flagship Missions, and Robotic Precursor Missions

- Foster external partnerships (e.g. other government agencies, academic, commercial, international)

- Each domain manages a diverse portfolio that includes both long-range and focused technology development activities

- Long-range technology investments are primarily selected via openly competed solicitations to gather many new, innovative ideas

- Focused development is primarily in-house, with partnerships, to ensure that technologies are integrated and infused into exploration missions, space industry, and national needs

\section{Demo Projects}

- Demos are activities that rise to the level of requiring a separate project management team, and independent cost and schedule requirements from the Foundational Technology Domains.

- Integrate multiple technologies into prototype systems for validation in a relevant environment

- Projects are selected to demonstrate key capabilities derived from architecture studies

- Draw upon technologies from Foundational Technology Domains

- Led by NASA project management team

- Will include competitively selected content and external $t \Sigma:$ :m members

- Limited life span (nominally 1-4 years)

- If flight is required on a Robotic Precursor or Flagships Mission those programs pick up the flight development costs 


\section{ETDD Structure}

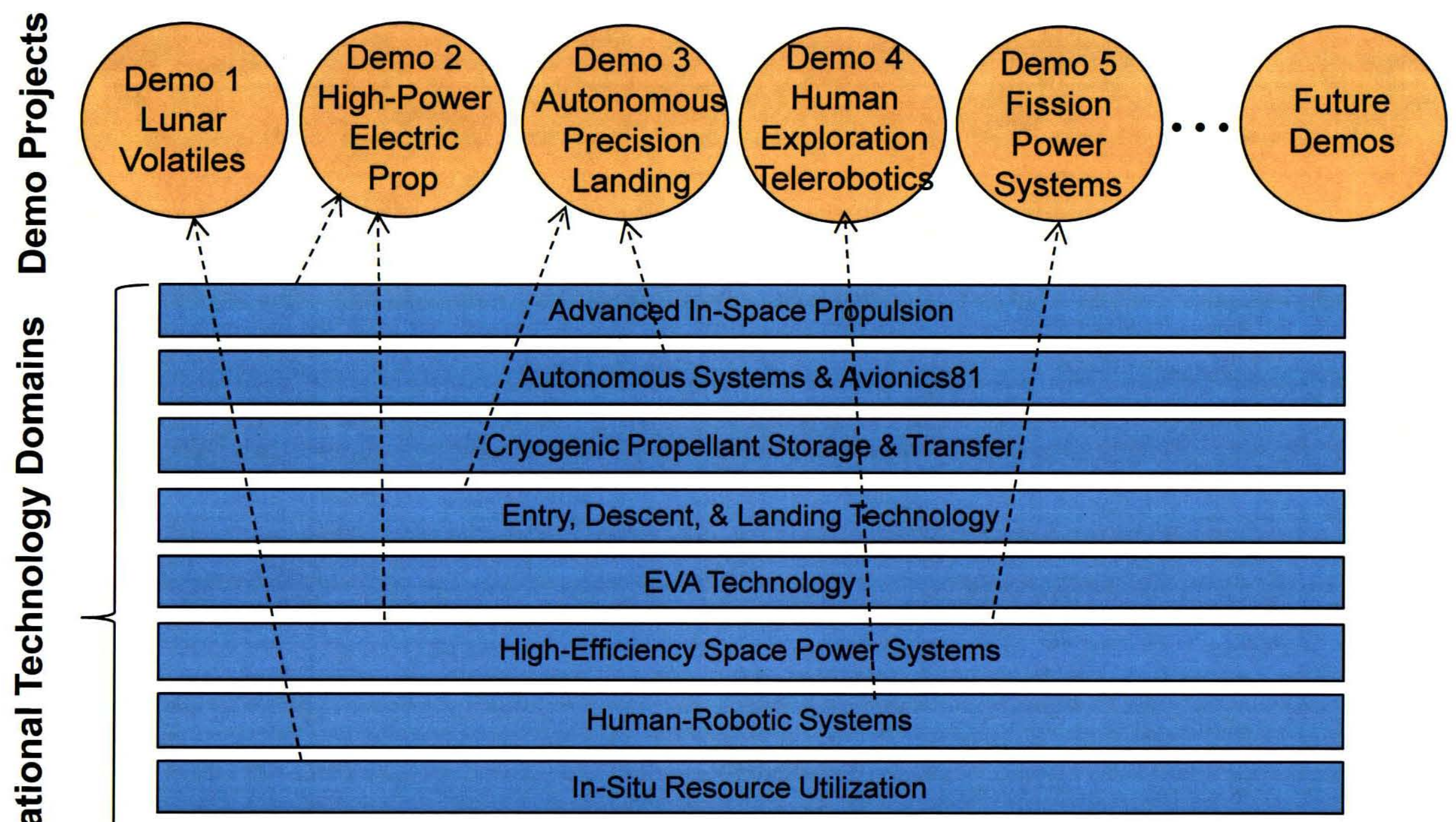

Life Support \& Habitation Systems

Lightweight Spacecraft Materials \& Structures 


\section{Foundational Technology Domains Address Long-Range Capability Needs for Multiple Destinations}

\begin{tabular}{|c|c|c|c|c|}
\hline & Moon & $\begin{array}{l}\text { Lagrange } \\
\text { Points }\end{array}$ & NEOs & Mars \\
\hline $\begin{array}{l}\text { Advanced In-Space Propulsion: Enabling low-cost and rapid transport of cargo and } \\
\text { crew beyond LEO. }\end{array}$ & $\checkmark$ & $\mathcal{V}$ & $\checkmark$ & $V$ \\
\hline $\begin{array}{l}\text { Autonomous Systems \& Avionics: Extending human exploration capability by } \\
\text { reducing workload and dependence on support from Earth. }\end{array}$ & $\checkmark$ & $\checkmark$ & $\checkmark$ & $V$ \\
\hline $\begin{array}{l}\text { Cryogenic Propellant Storage \& Transfer: Enabling the in-space infrastructure to } \\
\text { store and transfer propellants. }\end{array}$ & $\boldsymbol{V}$ & $\checkmark$ & $\checkmark$ & $V$ \\
\hline $\begin{array}{l}\text { Entry, Descent, \& Landing Technology: Landing large payloads safely and } \\
\text { precisely on extra-terrestrial surfaces and returning to Earth. }\end{array}$ & $V$ & & & $V$ \\
\hline $\begin{array}{l}\text { EVA Technology: Enabling humans to conduct "hands-on" surface exploration and } \\
\text { in-space operations outside habitats and vehicles. }\end{array}$ & $\boldsymbol{V}$ & $\checkmark$ & $\boldsymbol{V}$ & $V$ \\
\hline $\begin{array}{l}\text { High-Efficiency Space Power Systems: Providing abundant and low-cost power } \\
\text { where it is needed. }\end{array}$ & $\mathcal{V}$ & $\checkmark$ & $\boldsymbol{V}$ & $V$ \\
\hline $\begin{array}{l}\text { Human-Robotic Systems: Amplifying human productivity and reducing mission risk } \\
\text { by partnering humans and robots. }\end{array}$ & $\checkmark$ & $\checkmark$ & 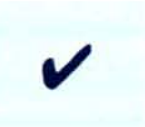 & $V$ \\
\hline $\begin{array}{l}\text { In-Situ Resource Utilization: Enabling sustainable human exploration by using local } \\
\text { resources. }\end{array}$ & $\mathcal{V}$ & & $\checkmark$ & $V$ \\
\hline $\begin{array}{l}\text { Life Support \& Habitation Systems: Enabling humans to live for long periods in } \\
\text { deep-space environments. }\end{array}$ & $\nu$ & $\nu$ & $V$ & $V$ \\
\hline $\begin{array}{l}\text { Lightweight Spacecraft Materials \& Structures: Enabling lightweight systems to } \\
\text { reduce mission costs. }\end{array}$ & $V$ & $V$ & $\checkmark$ & $V$ \\
\hline
\end{tabular}




\section{Initial Demonstration Projects}

In FY11, ETDD will initiate five demonstration projects that build upon current technology investments. Each project has been framed to address a key question for human exploration. The flight program will pay for the flight unit.

\section{- Lunar Volatiles Characterization:}

- Key Question: How can we locate, access, and extract volatile resources on the moon?

- This demonstration will verify the presence of water and other volatiles on the Moon by direct in-situ measurements of the lunar regolith. The project will build upon recent field tests of in-situ resource utilization (ISRU) technology by demonstrating operation of a prototype ISRU system in a thermal vacuum chamber. A flight experiment to demonstrate lunar resource prospecting, characterization, and extraction will be developed for testing on a Flagship or robotic precursor mission in 2015.

\section{- High-Power Electric Propulsion:}

- Key Question: How can we reduce travel time and cost for human deep-space exploration?

- This demonstration will design, build, and test a complete, sub-scale electric propulsion system scalable to the power levels $(>100 \mathrm{~kW})$ required to support human exploration missions. The thrusters will be integrated with a power management system and tested in a thermal vacuum chamber. This ground

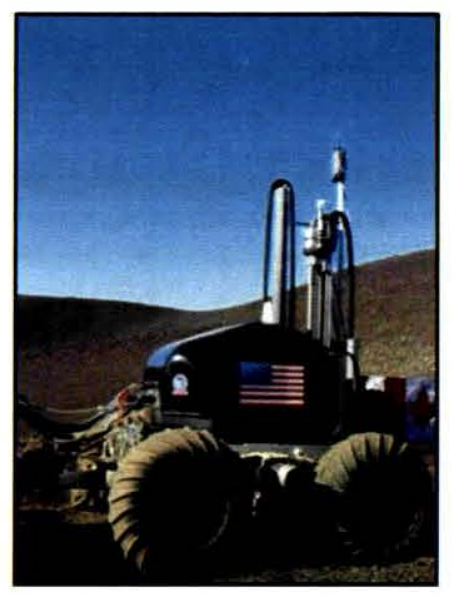
demonstration will support a solar electric propulsion system demonstration by the Flagship program in 2016. 


\section{Initial Demonstration Projects}

- Autonomous Precision Landing:

- Key Question: How can we land autonomously, precisely, and safely on a extra-terrestrial surface in uncertain environments?

- This demonstration will test an integrated autonomous landing and hazard avoidance system consisting of imaging sensors and navigation and control algorithms. NASA will develop an atmospheric flight experiment to demonstrate an autonomous precision landing and hazard avoidance system on a small lander test bed. NASA will pursue use of this system on a $U$. $S$. or international robotic precursor mission to the Moon or other planetary body around 2015.

\section{- Human Exploration Telerobotics:}

- Key Question: How do we use human-robotic partnerships to increase productivity, reduce costs, and mitigate risks?

- This demonstration will enable safe and cooperative interactions between humans and robots, and to extend human presence before human missions are ready. In 2011, the project will demonstrate teleoperation of multiple robots on the ground by crew on the International Space Station (ISS).

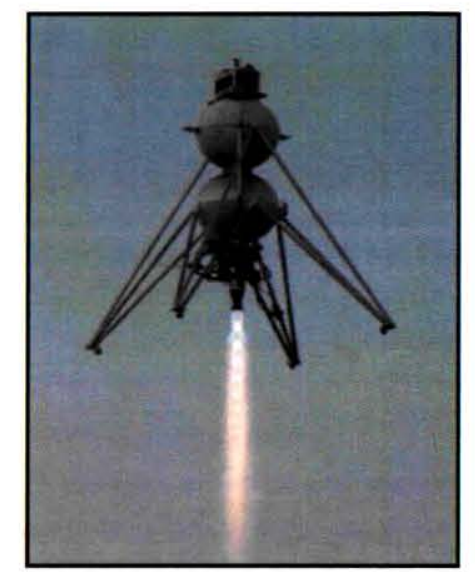

NASA KSC, william.e.larson@nasa.gov

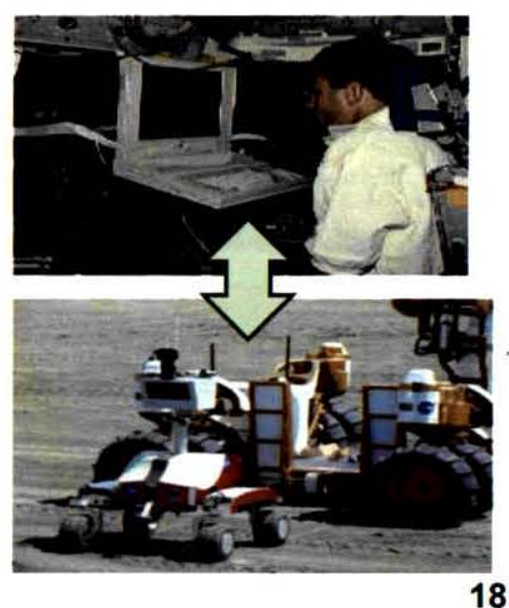




\section{Initial Demonstration Projects}

\section{(continued)}

- Fission Power Systems Technology:

- Key Question: How do we provide abundant, low-cost, and reliable electric power for long-duration missions?

- This demonstration will test power conversion and thermal management technologies for a $40 \mathrm{~kW}$ fission power system. The non-nuclear test will validate the performance of an integrated system consisting of Stirling power converters, a liquid metal coolant loop, and an advanced radiator in a thermal vacuum chamber.

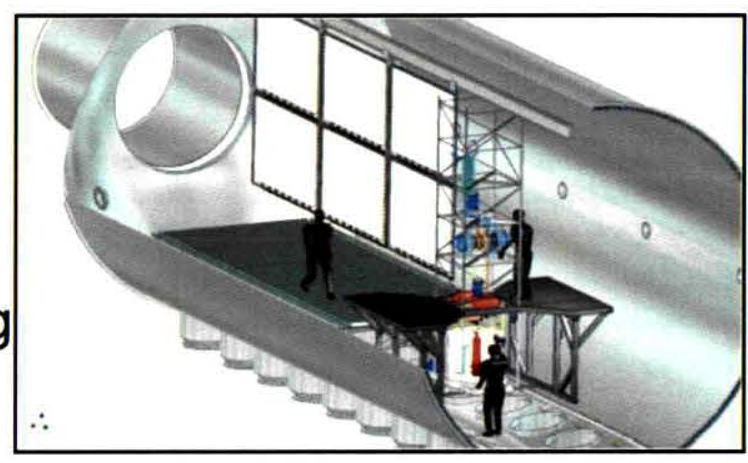




\section{Selection Rationale for Demonstration Projects}

- Rationale for Initial Demonstration Project Selections

- OMB Direction

- ISRU \& In-Space Propulsion

- ETDP Projects already planning demonstration

- Human Telerobotics

- Autonomous Landing \& Hazard Avoidance

- Key Enabling Technology

- Fission Power Demonstration

- Future Projects will be aligned with the critical capability needs identified in exploration architectural studies:

- Mars Design Reference Architecture 5.0

- Global Point of Departure Lunar Architecture

- Review of U. S. Human Space Flight Plans (Augustine) Committee

- Human Exploration Framework Team

- Projects will build upon technology investments made in the Domains.

- Projects will demonstrate major advances in capabilities within the next five years, making the first steps on long-range, strategic technology roadmaps.

- Projects will deliver technology products in time to support the major mission milestones in the Flagship Technology Demonstration Program and the Exploration Robotic Precursor Program. 


\section{ETDD Budget Profile}

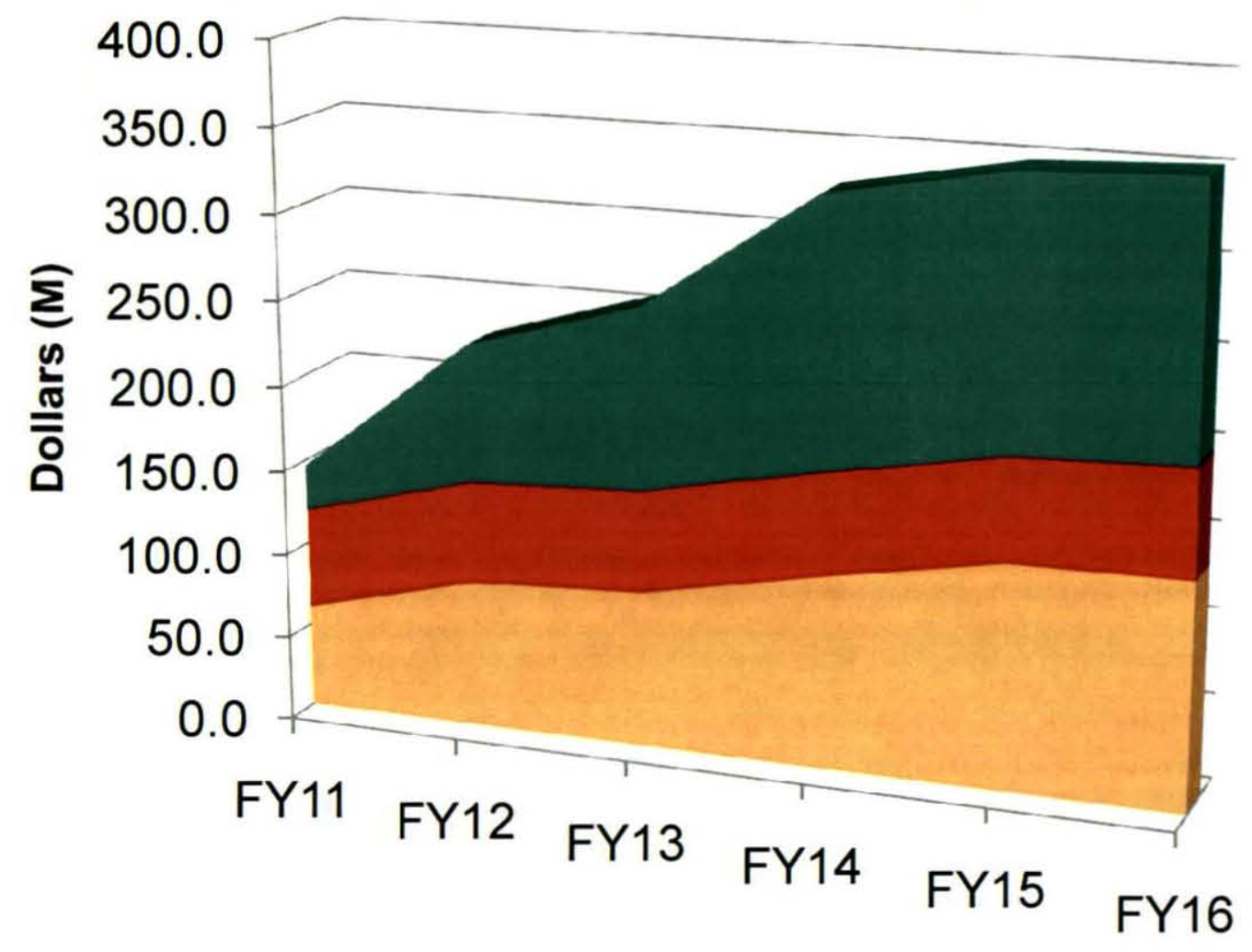

- Competed Technology Development

- Foundational Domains

Demonstration Projects 


\section{ETDD}

\section{Primary Relationships to Other Programs}

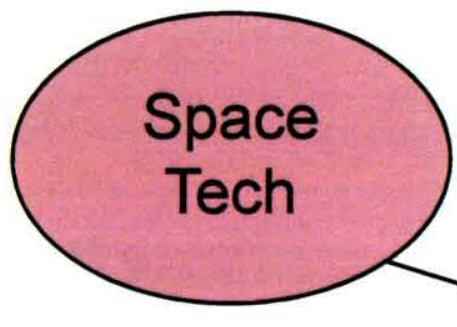

Early-stage, game-

changing, \& crosscutting

technologies

Partner on in-space demos

$\cdot$

Flagship

Demos

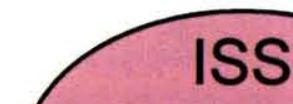

Research (SOMD)

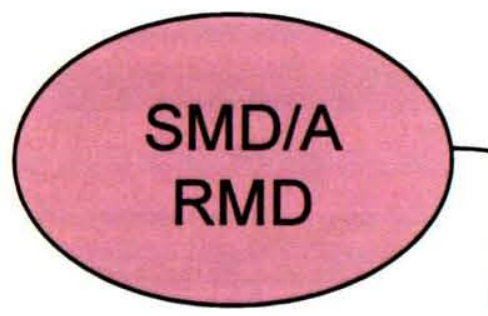

Coordination \& missions of

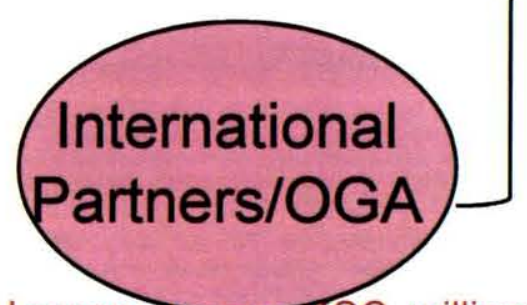
opportunity

Prototype systems for flight demos

Robotic Precursors 


\section{ETDD and Space Technology Programs}

$\begin{array}{lll}\text { Technology } & \text { ETDD } & \text { Space Technology } \\ \text { Driver } & \text { Mission Pull } & \text { Tech Push \& Innovation Infusion } \\ \text { Scope } & \text { Exploration Specific } & \text { Agency-wide; Broadly applicable } \\ \text { Maturity } & \begin{array}{l}\text { Components, Systems and } \\ \text { Operational Concepts (TRL 3-6) }\end{array} & \begin{array}{l}\text { Early-stage, Game-Changing, and } \\ \text { Crosscutting R\&D (TRL 1-6) }\end{array} \\ \text { Duration } & \begin{array}{l}\text { Long-lead tech; Knowledge } \\ \text { base for exploration }\end{array} & \begin{array}{l}\text { Rapid innovation through short- } \\ \text { duration projects }\end{array} \\ \text { Demonstrations } & \text { Small-scale, exploration specific } & \begin{array}{l}\text { Broadly applicable in partnerships } \\ \text { with Mission Directorates }\end{array}\end{array}$




\section{Space Technology Program: Relationship with Mission}

Directorate Technology Programs (e.g., ESMD)

Developing Technologies with Broad Applicability...

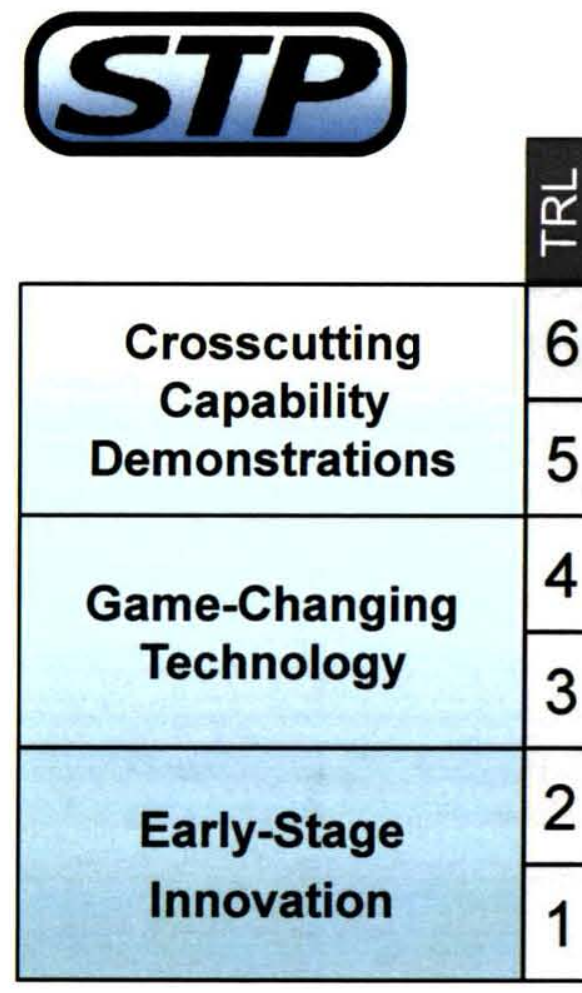

...to Support Mission-Specific Technology Needs.

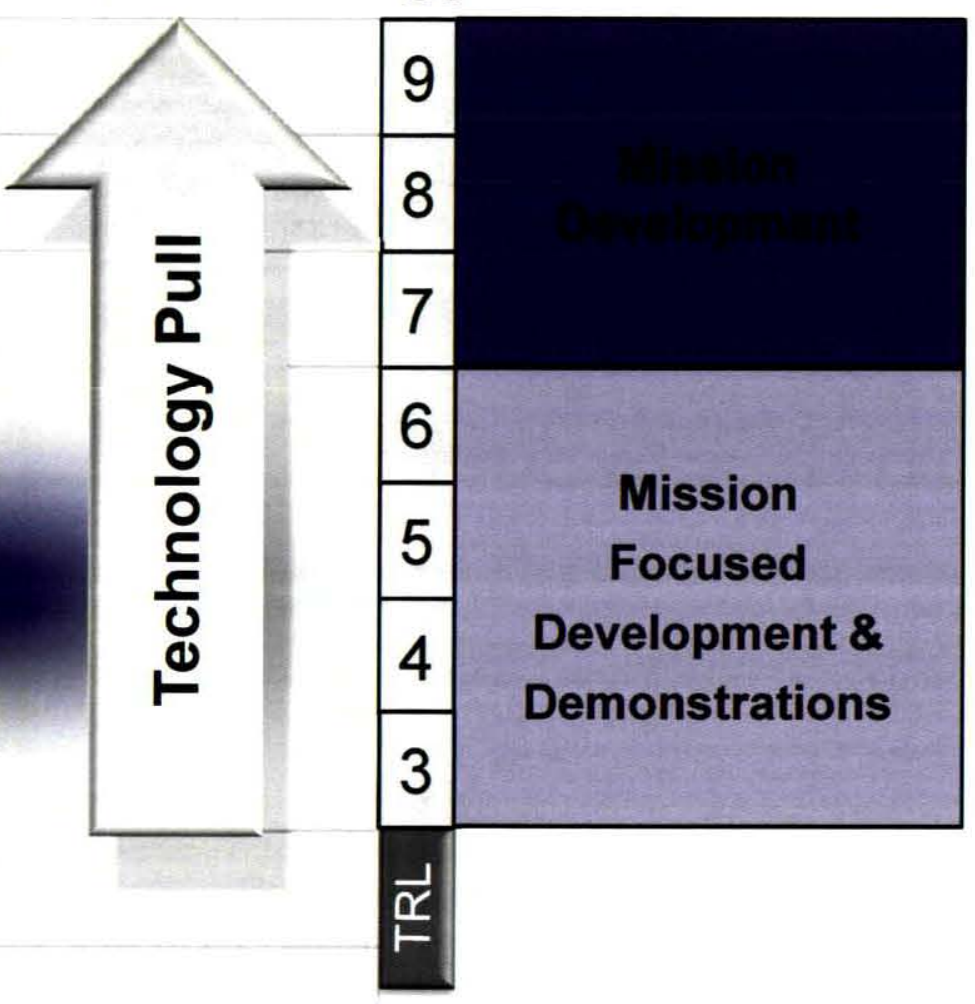




\section{OCT and ESMD Technology Program Elements}

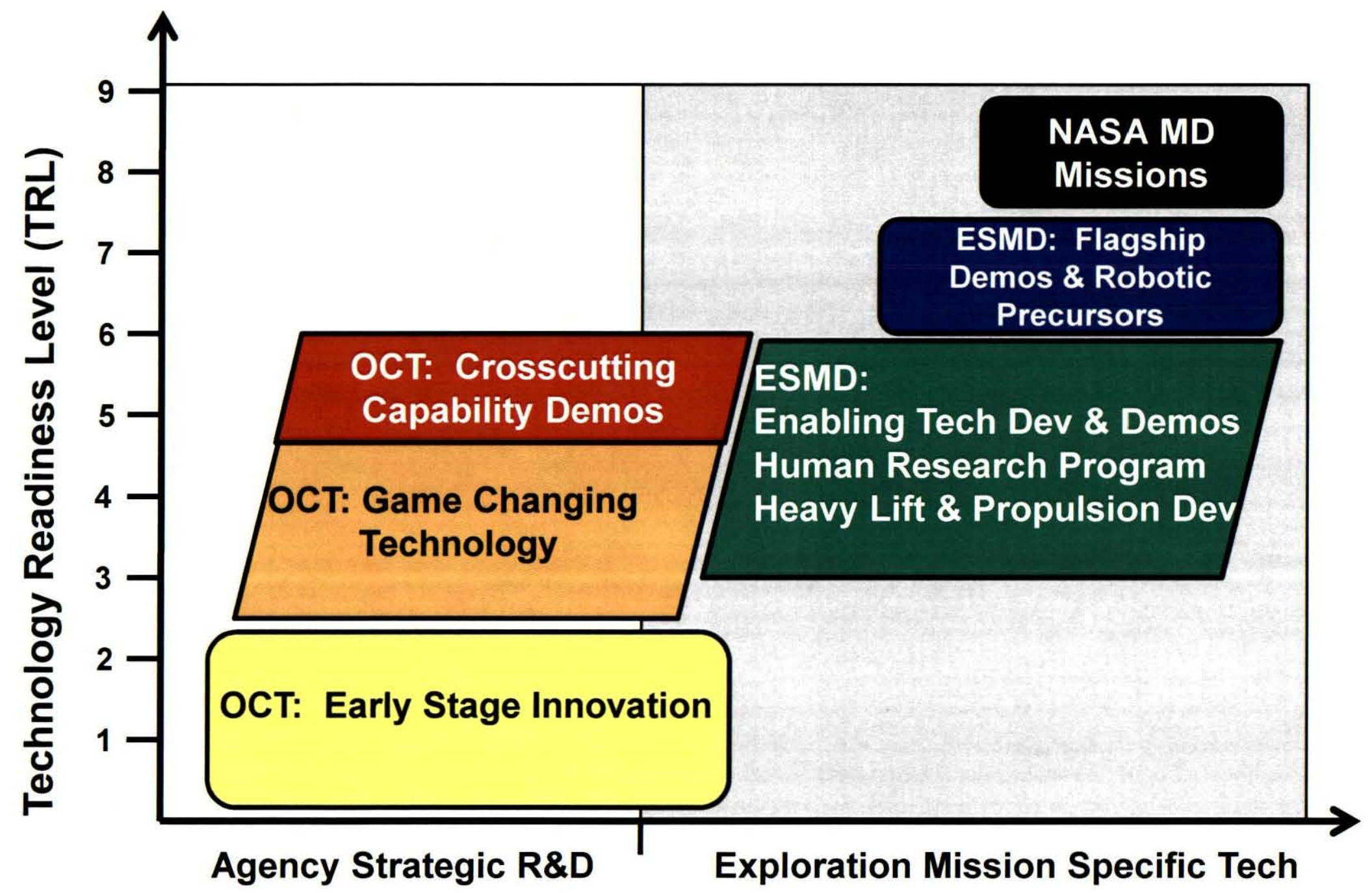

Scope of Applicability 


\section{Other Program Budgets with ISRU Impact}

All dollars in millions

\begin{tabular}{|l|c|c|c|c|c|}
\hline & 2011 & 2012 & 2013 & 2014 & 2015 \\
\hline Space technology & $\$ 572$ & $\$ 1,012$ & $\$ 1,060$ & $\$ 1,064$ & $\$ 1,218$
\end{tabular}

\begin{tabular}{|l|l|l|l|l|l|} 
& 2011 & 2012 & 2013 & 2014 & 2015 \\
\hline Robotic Precursors & $\$ 125$ & $\$ 506$ & $\$ 699$ & $\$ 797$ & $\$ 923$ \\
\hline
\end{tabular}

\begin{tabular}{|l|c|c|c|c|c|}
\hline & 2011 & 2012 & 2013 & 2014 & 2015 \\
\hline $\begin{array}{l}\text { Flagship Technology } \\
\text { Demonstrations }\end{array}$ & 424.4 & 953.4 & 1447.9 & 1569.3 & 1623.3 \\
\hline
\end{tabular}

This funding profile presents significant opportunities for ISRU activities 


\section{Flagship Technology Demonstrations}

\section{Administration Guidance:}

- NASA is directed to pursue three particular Flagship Technology Demonstration( FTD) and will propose, in coordination with OMB and OSTP, one additional demonstration to begin in 2011 (2010 if funding available)

- Selection will be made in full consultation with NASA's Chief Technology Officer

- The three principle FTDs:

- In-Orbit Propellant Transfer and Storage

- The capability to transfer and store propellant-particularly cryogenic propellant

- Lightweight/Inflatable Modules

- Automated/ Autonomous Rendezvous and Docking

- One additional FTD to begin in 2011 selected by NASA could include

- A closed loop life support system

- AeroCapture and/or entry, decent and landing (EDL) technology.

Flagship Technology Demonstrations 
The ISRU Project

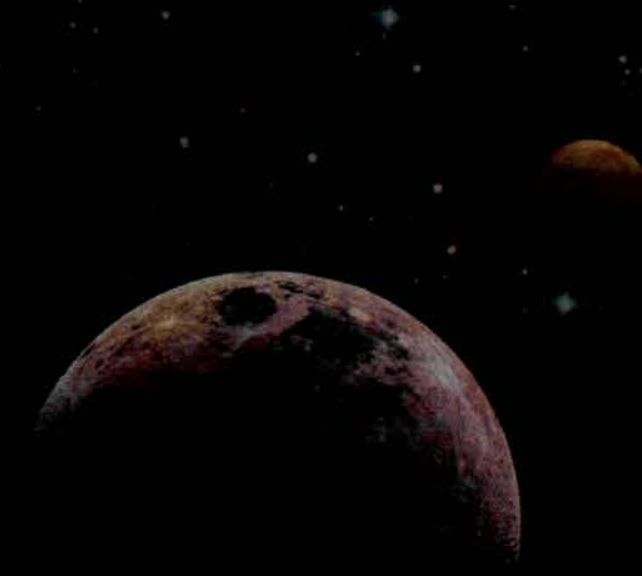




\section{All NASA Projects Need a Logo....}

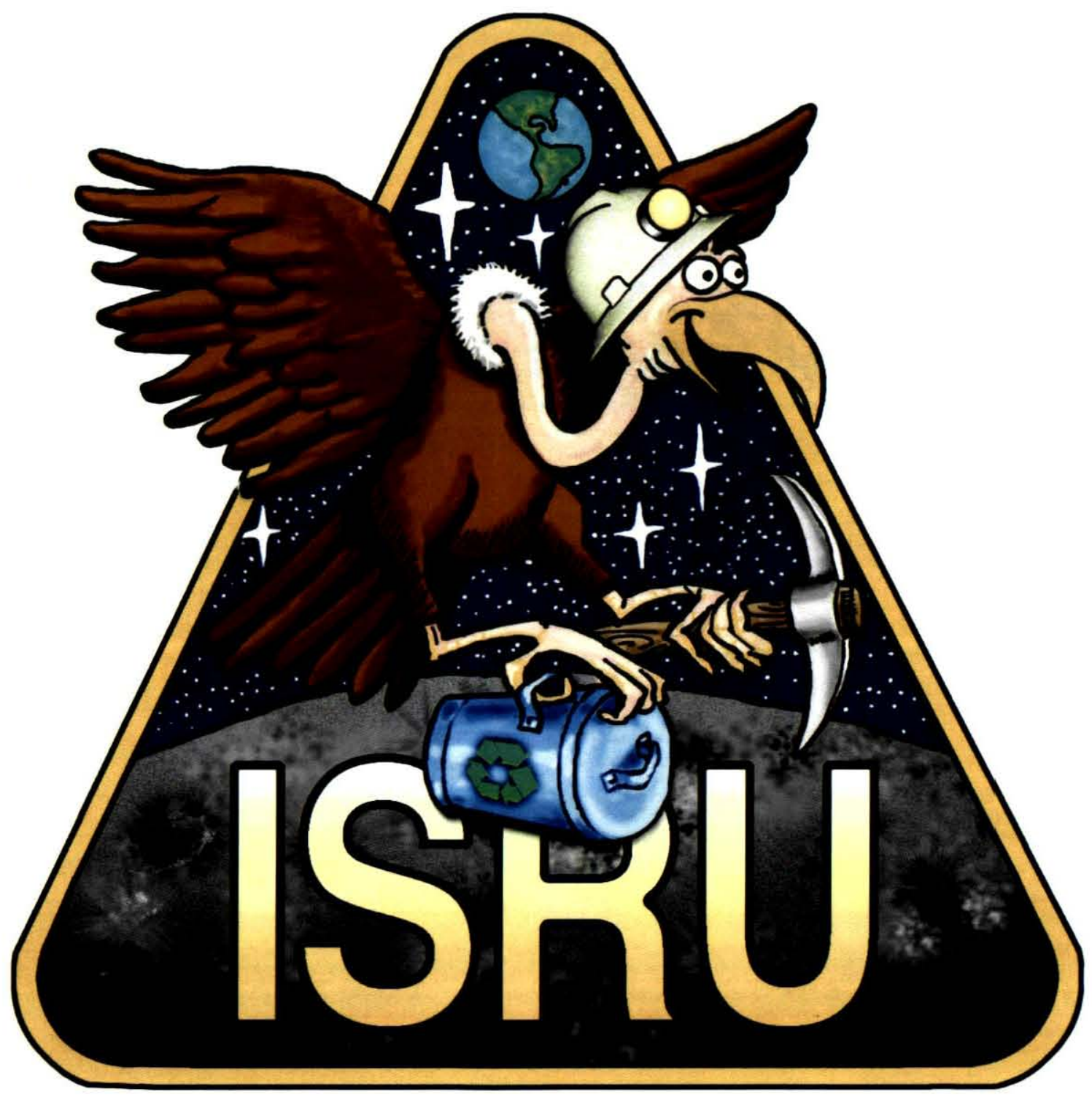




\section{ETDD ISRU Project Primary Objectives}

1. Provide the foundation and support for identification, selection, oversight, and system integration of in-house and competed technologies

2. Focus technology and system development to support ETDD Demos, XPRM, and Flagship flight demonstrations

3. Identify and promote development of technologies and systems in conjunction with other ETDD Domains, industry, academia, and International Partners

4. Support Architecture planning and development through analytical models and demonstrate ISRU capabilities at relevant mission scale through laboratory, analogue, and environmental simulation testing

5. Promote development of ISRU technologies and capabilities that address US energy and environmental challenges and foster terrestrial industry growth

6. Retain and develop critical skills within Agency for ISRU 


\section{Evolutionary Approach for ISRU Development}

Technology development philosophy

- Build a little, test a lot, modify to improve performance, repeat

Key Performance

Parameters (KPPs):

$>$ System mass per $\mathrm{kg}$ oxygen produced

$>$ System energy per $\mathrm{kg}$ oxygen/fuel produced

$>$ Difference between system and architecture

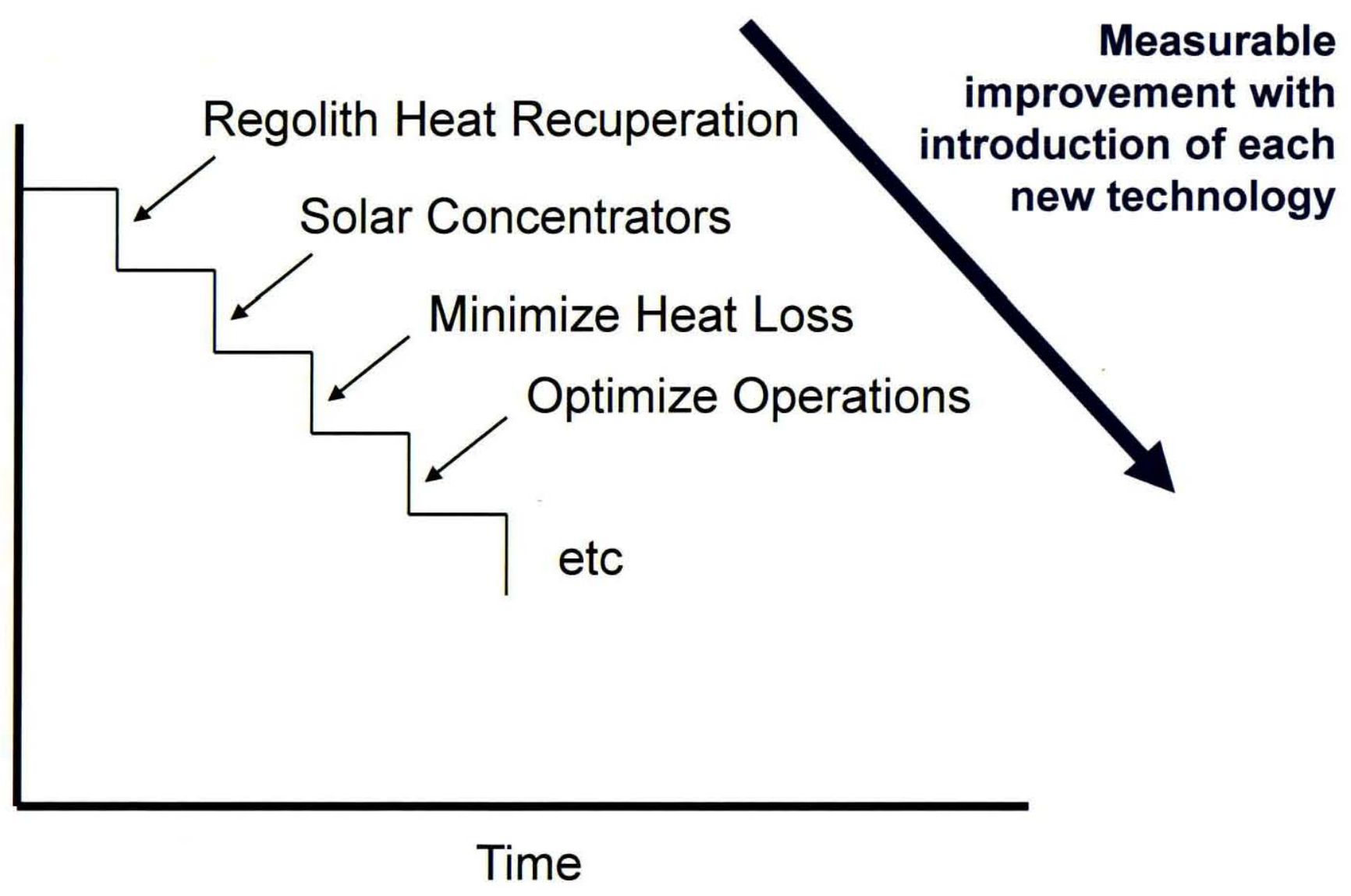




\title{
Idealized Roadmap for Evolutionary ISRU Campaign \\ Initial \\ Mid-Term
}

Long-Term

\author{
Resource \\ Assessment \\ - Remote \& Local \\ Sensors \\ - Simulants \\ In-Situ Resource \\ Excavation \& \\ Separation \\ - Regolith Excavation \\ - Thermal/Microwave \\ Extraction \\ - $\mathrm{H}_{2} \mathrm{O}$ Separation \\ - $\mathrm{CO}_{2} \& \mathrm{~N}_{2}$ Separation \\ Resource Processing \\ - Regolith Reduction \\ for $\mathrm{O}_{2}$ \\ - $\mathrm{CO}_{2}$ Reduction \\ - $\mathrm{H}_{2} \mathrm{O}$ Reduction \\ - Fuel Production \\ Consumable Storage \\ \& Distribution \\ - Cryocoolers \\ - Light Weight Tanks \\ - Disconnects/pumps \\ - Transfer/Distribution \\ In-Situ Manufacturing \\ - Metal Feedstock \\ Production \\ - Metallic part fab \\ - Polymer part fab. \\ - Ceramic part fab. \\ - Solar cell production \\ - Manufacturing NDE
}

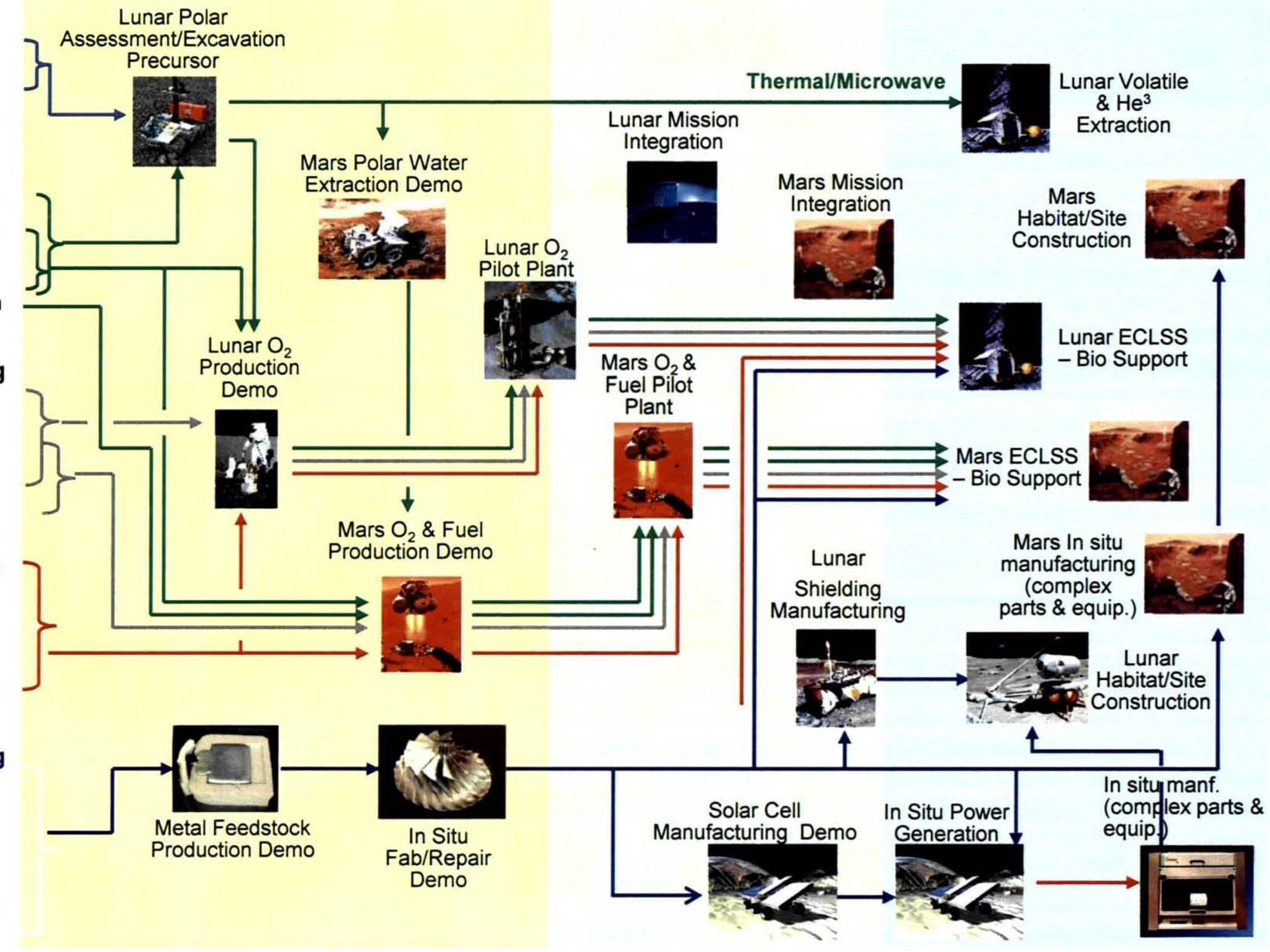




\section{Reality vs. Idealized Roadmap}

- Reality, for a change, isn't so bad for the ISRU project at this juncture.

- XPRP has been directed to include ISRU on their 2015 Lunar Lander

- Mission Definition is still under discussion, but will involve ground truth for lunar water, a lunar oxygen production demonstration, or both.

- Flagships Program is planning a Mars Lander for 2018.

- 2018 orbits provide the largest payload capacity for a landed mission in 30 years.

- ISRU is being included in the planning for this mission.

- NEO rendezvous missions are planned (dates are still a bit uncertain, but there is a possibility of two NEO missions this decade.

- ISRU prospecting payloads are a distinct probability on one or both missions.

- ISS Inflatable Habitat Demonstrations in the mid to latter part of the decade provide an opportunity for ISRU to demonstrate Trash Processing technologies 


\section{WBS 2.0 Oxygen Production}

\section{Description}

Purpose: Develop technologies to produce oxygen from planetary regolith and atmosphere

\section{Description}

- Produce oxygen from regolith by breaking the oxygen bond via chemical or biological processes in minerals found in planetary regolith

- Capture CO2 from Mars Atmosphere

- Produce oxygen from Mars atmospheric $\mathrm{CO} 2$ from a variety of chemical or electrochemical means

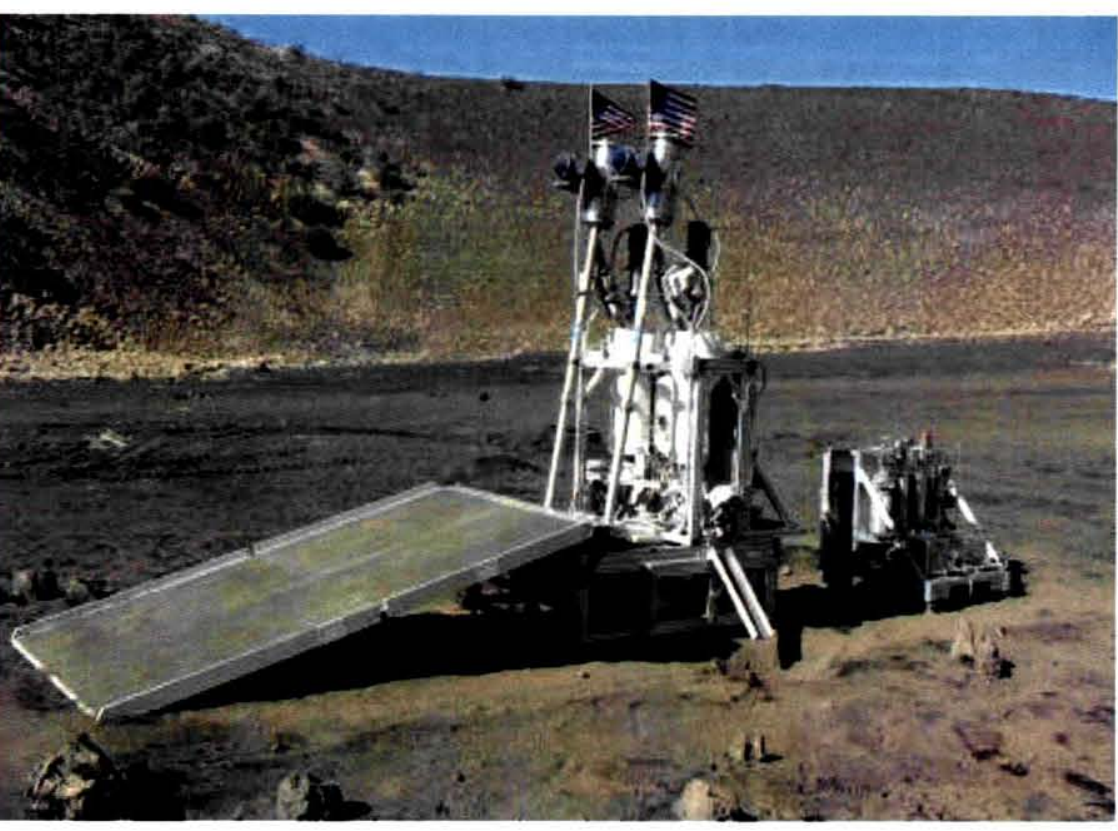

Lunar O2 Production System Under Test at Lunar Analog

\section{FY11-13 Objectives}

- Determine feasibility of biological reduction of regolith in FY11

- Pursue in 12 \& 13 if practical and scaleable via BAA

- Determine practicality of biological processes for waste processing (food, human, plastics, etc.) for in FY12 \& 13

- Initiate State of the Art Study on Mars atmospheric processing technologies (captured under the Systems Integration Budget WBS 5)

*NOTE: Atmospheric Capture and Separation work is required in this area and also in Fuel and Water Production WBS, for planning purposed it is carried under WBS 7 in this budget submit 


\section{WBS 3.0 ISRU Thermal Energy}

Description

Purpose: Develop technology to acquire and utilize thermal energy for ISRU process

\section{Description}

- Develop innovative technologies and methods for utilizing thermal energy within ISRU process reactors

- Develop high efficiency methods for delivering thermal energy to ISRU process systems

- Develop thermal energy storage technologies utilizing codeveloped ISRU processes

- Develop lightweight solar-thermal energy capture technologies

\section{Objectives}

- High-efficiency propellant and water production on ISS and Mars

- Prepare for Flagship or Robotic Precursor technology demonstration

- Produce terrestrial spinoffs in energy technologies

\section{Approach}

- Identify the SOA in sub-system technologies and components:

- Heat pipe and fiber-optic bundles

- High efficiency mixing and heat transfer in reactors

- Radiatively coupled exchange between thermal energy reservoirs and end user processes.

- Thermal energy storage in extra-terrestrial environments

- Lightweight solar concentrators

- Conduct selected in-house laboratory development to prepare as smart buyer and system integrator

- Collaborate with related ETDD domains: Power and Life Support

- Collaborate with related NASA and other agency R\&D programs

- Formulate, execute and integrate development efforts under competed BAA opportunities, SBIR, and STD.

\section{Collaborators}

NASA (Power, ELS, ASRD), DOE

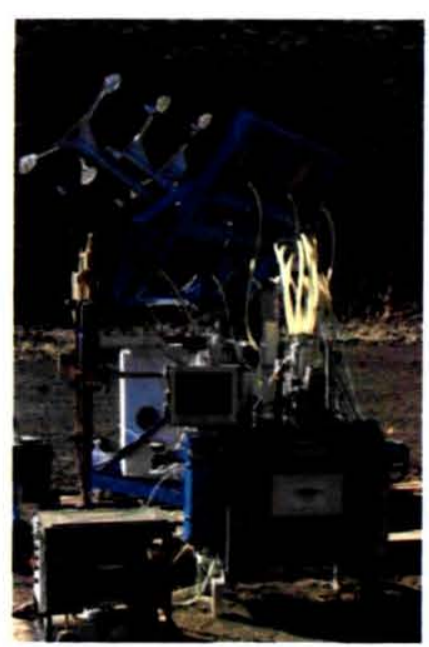

Solar Concentrator /Carbothermal Reactor in Mauna Kea Field Trials

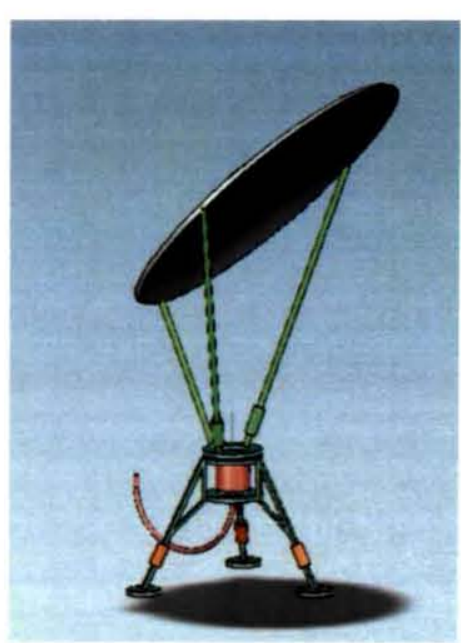

Direct solar heating of trash processing or water extraction reactor

\section{FY11-13 Objectives}

- Test effectiveness of Heat Pipe Technology Delivered from SBIR program in various ISRU reactor concepts

- Investigate technologies for utilizing direct solar thermal energy for ISRU processes

- Integrate best design concepts into robotic scale designs for both lunar and Mars payload designs

- Invest small amount of funds in the co-funding of some synthetic fuel production technologies that utilize solar thermal energy take atmospheric $\mathrm{CO} 2$ and produce fuels with no energy input other than solar. 


\section{WBS 4.0 Systems Engineering}

\section{Description}

Purpose: Provides funding for systems engineers to perform the design work to integrate subsystem development into systems for laboratory and analog test

\section{Description}

- Design Mars Atmospheric Capture and Oxygen Production System

- Design Trash Processing System to convert refuse into fuel or water

- Design Mars Fuel Production System

- Design Mars Water Extraction System for Hydrogen production

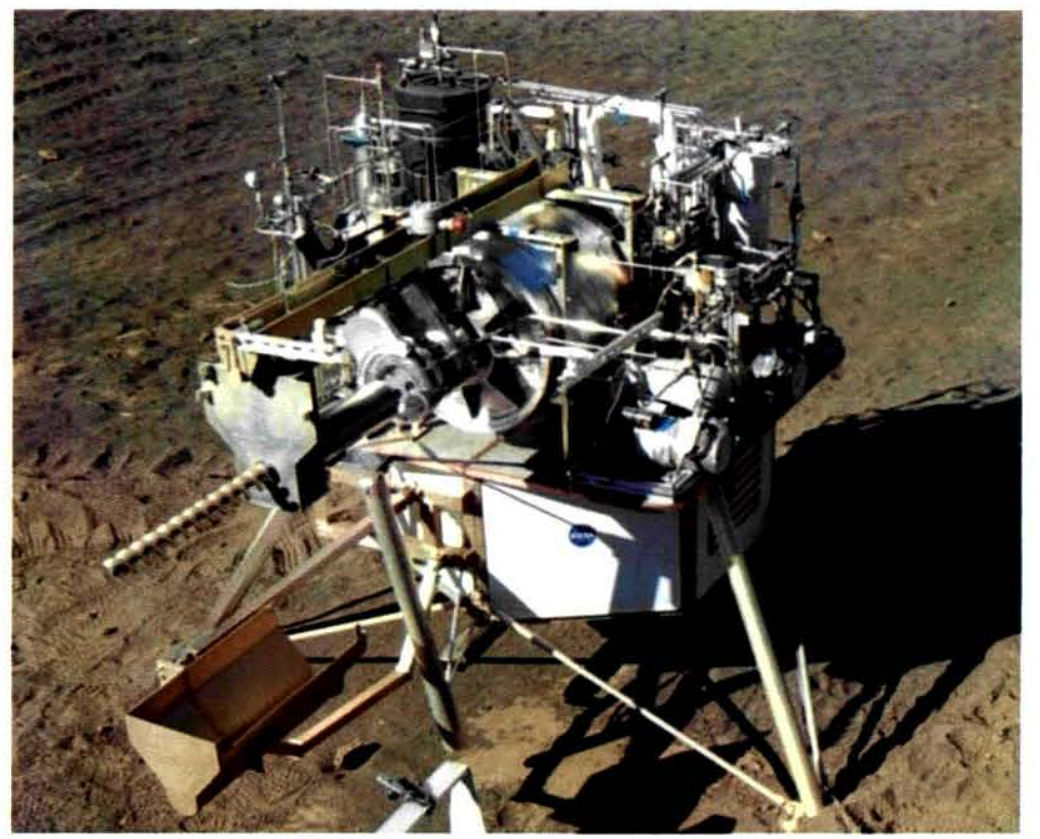

Integrated Lunar O2 Production System on Lander Mockup

FY11-13 Objectives

- No FY11 tasks in Systems Engineering only technology level funding in the other WBS elements

- Systems Engineering tasks will begin in FY12 and run for roughly three years each

- Mars Water Processor Reactor will be first systems engineering task (FY12 start)

- Mars Trash and Fuel Production will begin in FY13

- Some Domain funded support will be provided to the robotic oxygen production system assumed to be funded by $X$ PRP 


\section{WBS 5.0 ISRU System Integration}

\section{Description}

- Create, upgrade, and validate analytical models for each ISRU system component

- Use analytical models to guide hardware designs and testing

- Support integrated tests in lab, environmental simulation, and analog

- Support architecture studies

- Fund laboratory tests of integrated hardware in laboratory and analog locations

- Perform trade studies to ascertain the State of the Art of important technologies

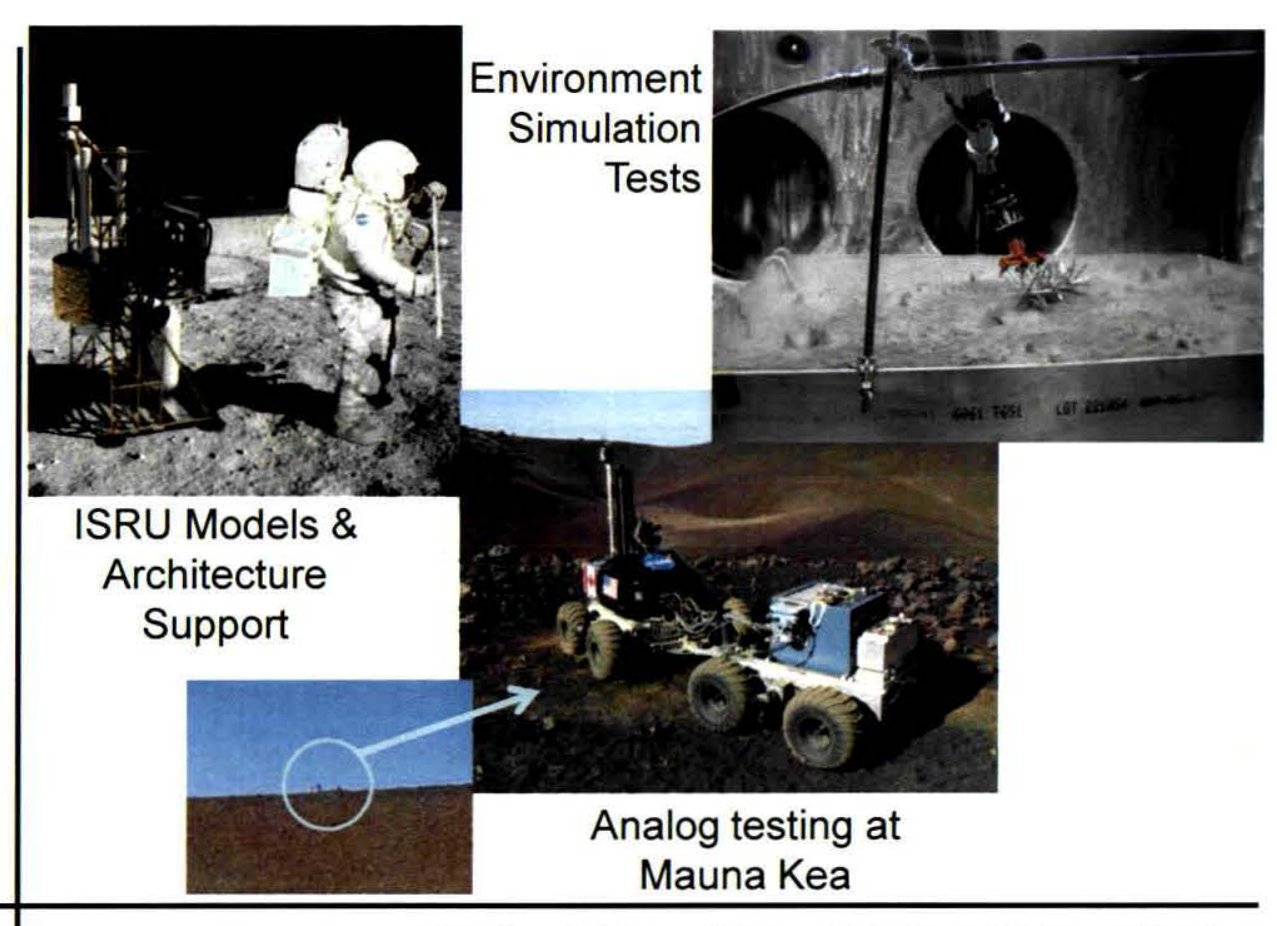

Approach

- Upgrade and validate existing component models and develop Mars-specific components and systems

- Resource acquisition-excavation and atmosphere capture

- Reactors

- Balance of plant

- Product conditioning, storage, and delivery

- Conduct coordinated laboratory, environmental simulation, and analog demonstrations to validate models and prepare for flight

- Collaborate with mission architecture teams to ensure ISRU is integral to missions

- Collaborate with related domains to develop integrated efforts in common technologies (thermal mgt, electrolysis, dust mgt, mobility, power/energy, etc.)

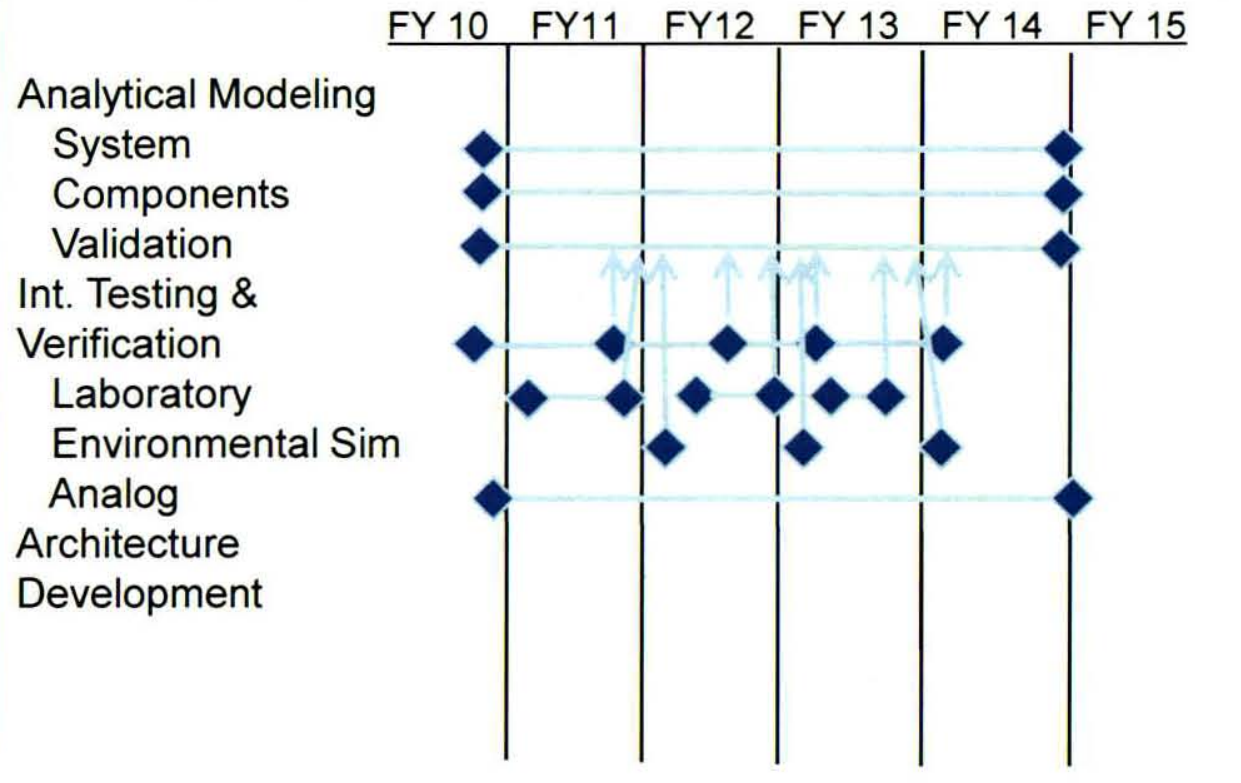




\section{WBS 6.0 Regolith Delivery Systems}

\section{Description}

Purpose: Investigate granular material flow, simulants and develop subsystems to deliver regolith to the processing reactor

\section{Description:}

- Development of regolith delivery systems for lunar, mars and NEO applications

- Research of granular materials and their flow characteristics

- Development of regolith simulants

- Development of regolith size sorting and beneficiation subsystems

- Research of design concepts for components that have to interact with the regolith

\section{Approach}

- Study behavior of granular materials and develop models that will aid in the design of regolith delivery subsystems

- Investigate and develop as necessary simulants for planetary regolith

- Develop size sorting subsystems to deliver the correct size particle to the reactor

- Develop beneficiation subsystem that delivers enhanced mineral concentrations to reactors

- Develop delivery subsystem to move regolith from delivery hopper into on with regolith

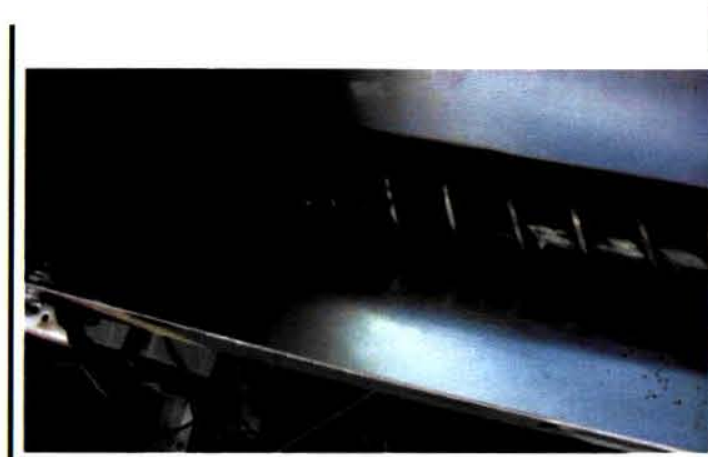

Regolith Delivery Auger under test in Hawaii

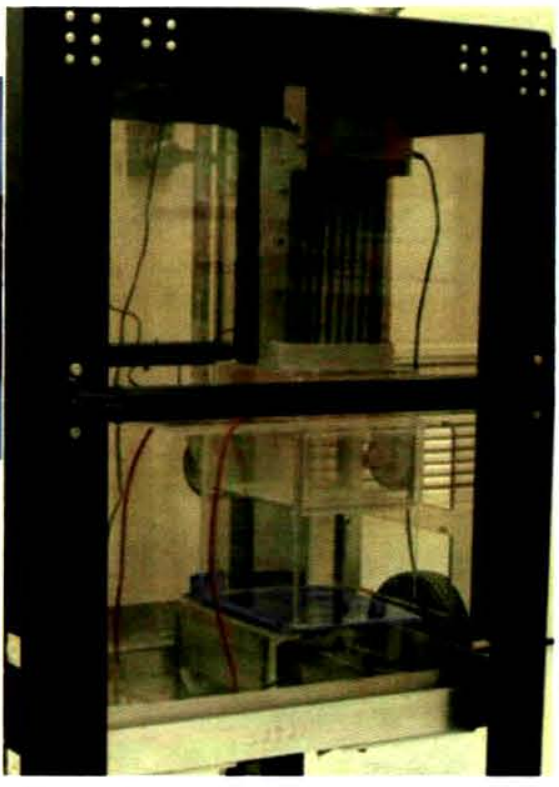

Beneficiation Test Article Ready for Reduced Gravity

\section{FY11-13 Objectives}

Flight

- FY11

- Design Demonstration Scale Beneficiation System test with Lunar Volatiles Reactor to determine efficiency (not integrated)

- Evaluate Size Sorting Techniques in the Laboratory

- Design Regolith Delivery System for robotic -scale O2 system

- FY12

- Integrate and test prototype Beneficiation system with $\mathrm{O} 2$ Production Reactor (Lunar Volatiles or XPRP)

- Integrate and test prototype Regolith Delivery System with O2 Production Reactor

- Build Size Sorting prototype integrate with O2 Reactor

- FY13

- Design, build and integrate final Delivery, size sorting and beneficiation system for lunar oxygen production robotic scale reactor 


\section{WBS 7.0 In-Space Fuel and Water Production}

\section{Description}

Purpose: Develop technology to produce fuels and water from waste/trash, the Martian atmosphere and soil, and scavenged hydrogen

\section{Description}

- Decompose trash and waste materials into fuel synthesis feedstock

- Capture atmospheric Carbon Dioxide (CO2)

- Separate gas species and filter dust from collected atmosphere

- Extract water from Martian Soil

- Decontaminate water and collect for storage

- Obtain Hydrogen (H2) from water and scavenged propellant

- Synthesize methane and higher hydrocarbons

\section{Approach}

- Identify the SOA in sub-system technologies and components:

- $\mathrm{CO} 2$ capture and gas separation

- H2O separation methods

- Fuel species formulation from trash/waste feedstock, atmospheric $\mathrm{CO} 2$, and $\mathrm{H} 2 \mathrm{O}$

- Conduct selected in-house laboratory development to prepare as smart buyer and system integrator

- Collaborate with closely related ETDD R\&D efforts, especially including life support and propulsion systems.

- Collaborate with related R\&D programs within NASA (e.g. ASMD Bio-fuels) and other agencies (e.g. DOE, DOD, etc.)

- Formulate, execute and integrate development efforts under competed BAA opportunities, SBIR, and STD.

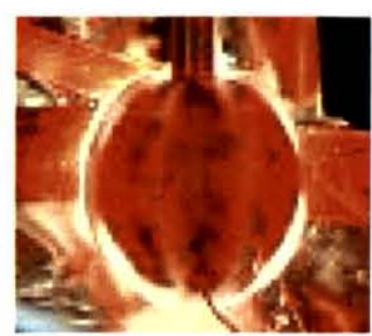

$\mathrm{CO}_{2}$ Freezer for

Atmospheric Acq.

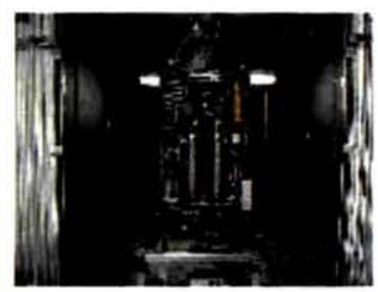

SabatierMater Electrolysis

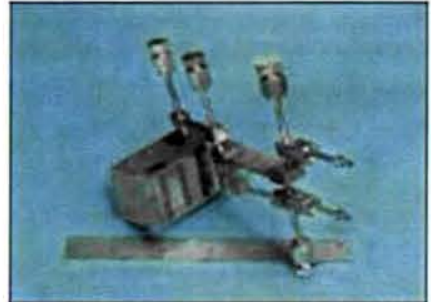

Microchannel Sabatier-RWGS Reactor Prototype

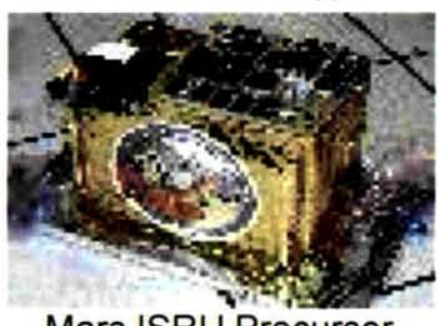

Mars ISRU Precursor (MIP) Flight

\section{FY11-13 Objectives}

- Continue regenerative water clean up research (reactors produce "dirty water"'), breadboard solutions in $12 \& 13$

- Support O2 Robotic Design with non-regenerative designs

- Restart membrane separation work for gas (Supports Sabatier, RWGS and CO2 Electrolysis), integrated with systems as available

- Research anaerobic trash processing methods for fuel/water production, build breadboards and test in 12\&13

- Initiate regenerable dust filtering work for Mars atmosphere capture, integrate into atmospheric capture designs when delivered by contractors

- Initiate lab experiments utilizing microwave heating to extract water from Mars soils

- Study design of water extraction from Mars soil "reactor" breadboard in 12, prototype in 13 


\section{WBS 8.0 Feedstock and Part Manufacturing}

\section{Description and Objectives}

Purpose: Develop technology to produce metals and plastics needed as feedstock for parts manufacturing

\section{Description}

- Development of technology to reduce planetary minerals into pure metals

- Work in conjunction with the trash processing project to produce plastics that can be used for feedstock or radiation shielding

- Develop systems that can produce parts from Feedstocks

\section{Approach}

- Continue funding constrained development of extraction design for Molten Regolith reactor

- Deemphasize oxygen caption and focus instead on pure metals production

- Utilize BAA competitive process to utilize industry and academia to advance the electrolysis process

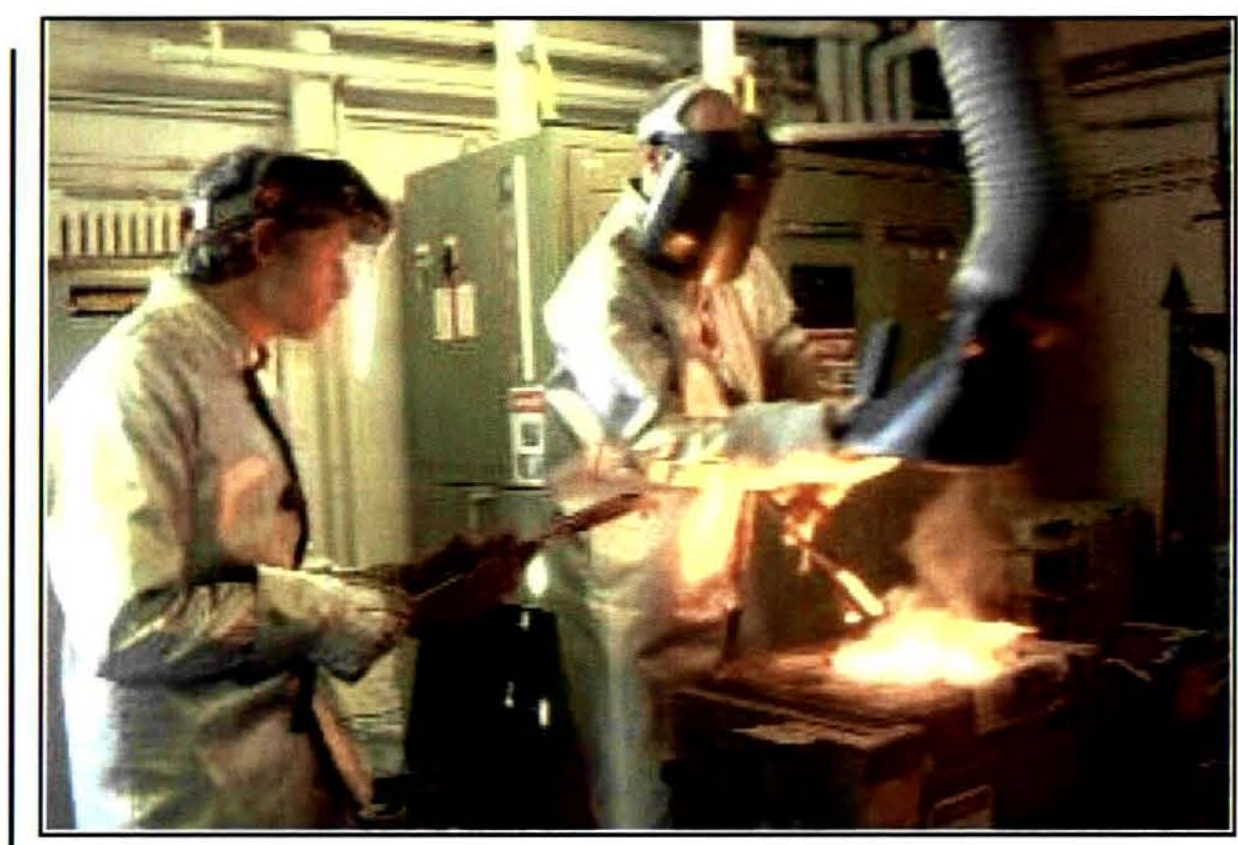

Metals Extraction from Reactor Experiment

FY11-13 Objectives

- Design, test Metals Extraction Mold Concept (FY11)

- Award BAA to continue Molten Oxide Electrolysis cell design (FY12)

- Design \& test prototype selective metals extraction from reaction cell ( make pure iron, silicon and aluminum) [FY12\& 13)

- Design prototype self heating cell with integrated feed and removal technology (FY14 -16) [assumes BAA funding available] 


\section{Summary}

- New NASA Exploration Program Provides Rich Development Opportunities for ISRU

- Foundational area will provide a stable source of funding for NASA to maintain skills and integrate technologies being delivered by the competitive process.

- Competitive funding wedge in both ETDD and STP will allow us to pursue innovative approaches to ISRU

- Demonstration Projects within ETDD provide opportunities for ISRU to continue its field demonstration program, but more importantly opportunities for flight demonstrations

- By the end of the decade the ISRU project could realistically have flown four demonstration or prospecting payloads! 
ISRU is moving into the mainstream. It's about time, don't you think!

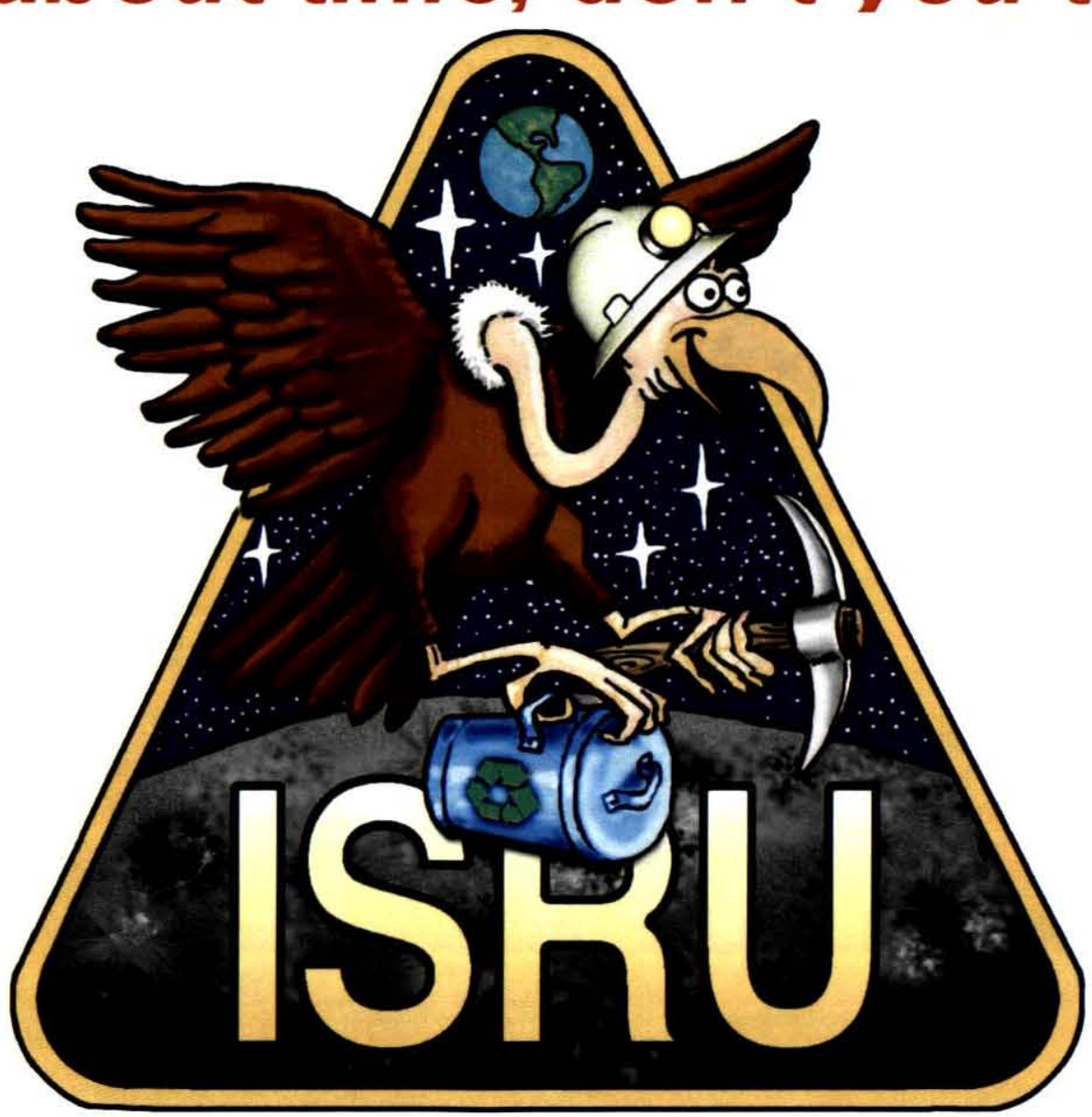




\section{ISRU Work Breakdown Structure (FY11+)}

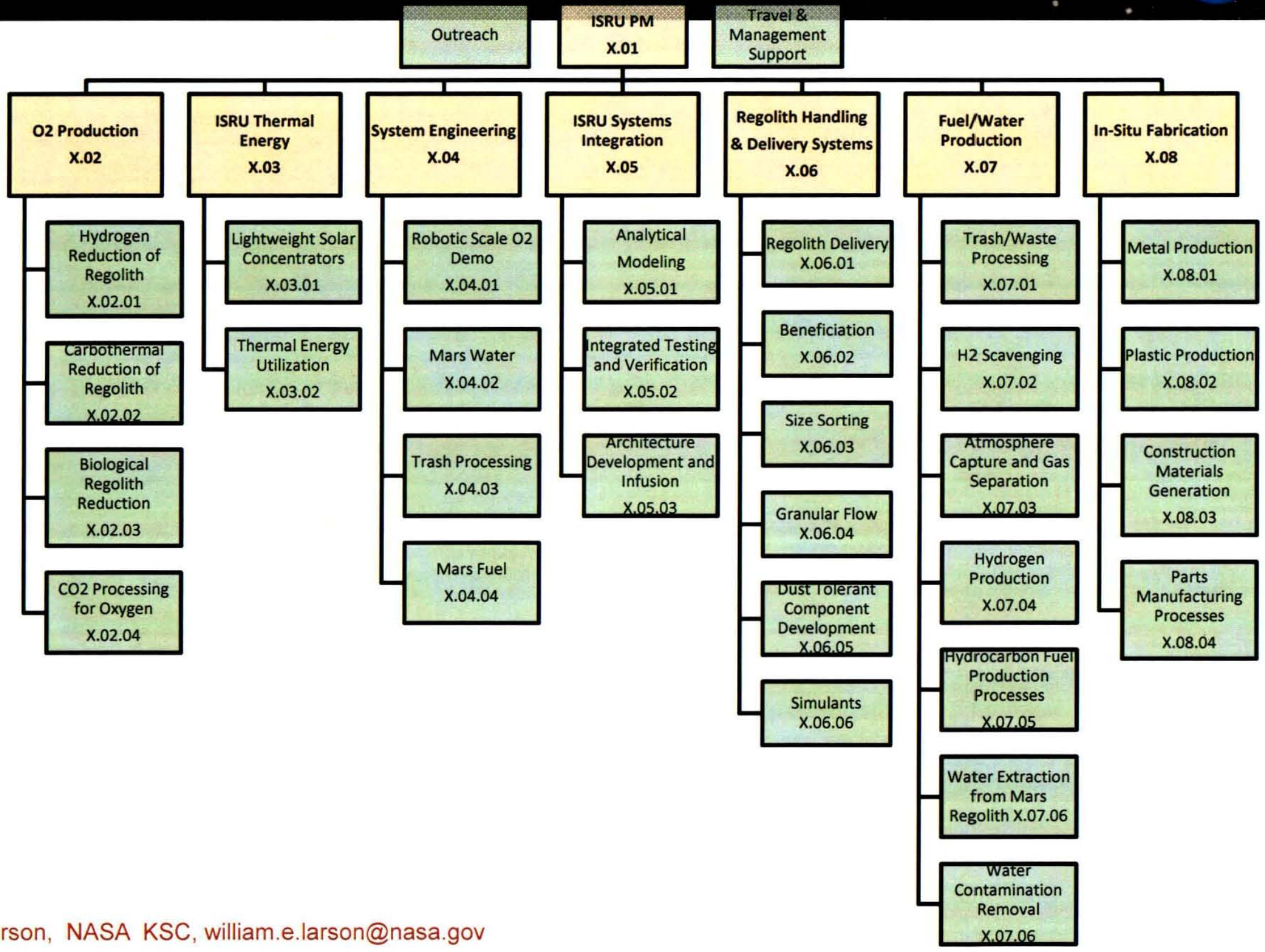

